San Jose State University

SJSU ScholarWorks

Master's Theses

Master's Theses and Graduate Research

1993

\title{
Home activity program compliance in trauma patients with upper extremity joint stiffness
}

Hazel M. Horti

San Jose State University

Follow this and additional works at: https://scholarworks.sjsu.edu/etd_theses

\section{Recommended Citation}

Horti, Hazel M., "Home activity program compliance in trauma patients with upper extremity joint stiffness" (1993). Master's Theses. 546.

DOI: https://doi.org/10.31979/etd.4rtp-52vp

https://scholarworks.sjsu.edu/etd_theses/546

This Thesis is brought to you for free and open access by the Master's Theses and Graduate Research at SJSU ScholarWorks. It has been accepted for inclusion in Master's Theses by an authorized administrator of SJSU ScholarWorks. For more information, please contact scholarworks@sjsu.edu. 


\section{INFORMATION TO USERS}

This manuscript has been reproduced from the microfilm master. UMI films the text directly from the original or copy submitted. Thus, some thesis and dissertation copies are in typewriter face, while others may be from any type of computer printer.

The quality of this reproduction is dependent upon the quality of the copy submitted. Broken or indistinct print, colored or poor quality illustrations and photographs, print bleedthrough, substandard margins, and improper alignment can adversely affect reproduction.

In the unlikely event that the author did not send UMI a complete manuscript and there are missing pages, these will be noted. Also, if unauthorized copyright material had to be removed, a note will indicate the deletion.

Oversize materials (e.g., maps, drawings, charts) are reproduced by sectioning the original, beginning at the upper left-hand corner and continuing from left to right in equal sections with small overlaps. Each original is also photographed in one exposure and is included in reduced form at the back of the book.

Photographs included in the original manuscript have been reproduced xerographically in this copy. Higher quality $6^{\prime \prime} \times 9^{\prime \prime}$ black and white photographic prints are available for any photographs or illustrations appearing in this copy for an additional charge. Contact UMI directly to order.

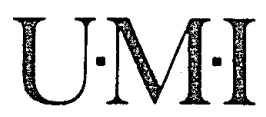



Order Number 1853023

Home activity program compliance in trauma patients with upper extremity joint stiffness

\author{
Horti, Hazel M., M.S. \\ San Jose State University, 1993
}

Copyright (C)1993 by Horti, Hazel M. All rights reserved.

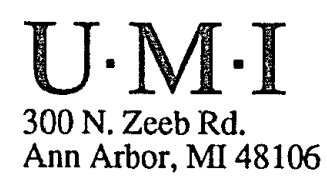





\title{
HOME ACTIVITY PROGRAM COMPLIANCE IN TRAUMA PATIENTS \\ WITH UPPER EXTREMITY JOINT STIFFNESS
}

\author{
A Thesis \\ Presented to \\ The Faculty of the Department of Occupational Therapy \\ of San Jose State University
}

In Partial Fulfillment

of the Requirements for the Degree

of Master of Science

\section{by}

Hazel M. Horti

May, 1993 
APPROVED FOR THE DEPARTMENT OF OCCUPATIONAL THERAPY

Lela Q. L Shines

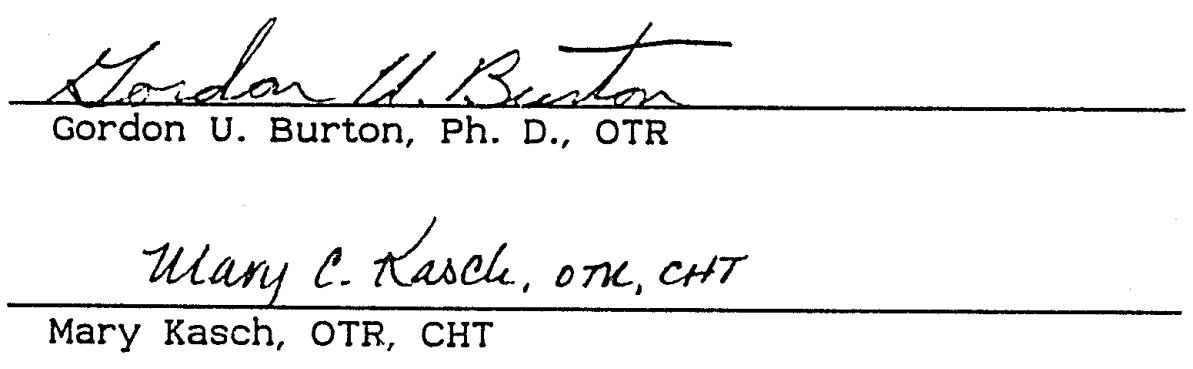

APPROVED FOR THE UNIVERSITY

Serena It. tanjore 
(C) Copyright 1993

Hazel M. Horti

All Rights Reserved 


\section{ABSTRACT \\ Home Activity Program Compliance \\ in Trauma Patients with Upper Extremity Joint Stiffness}

by Hazel M. Horti

This thesis addresses the issue of compliance with prescribed home program activities by patients engaged in hand rehabilitation and explores the relationship between compliance and the patients' gains in joint mobility. A multiple case study design was used to collect and analyse the data. Eight patients with stiff upper extremity joints were instructed to perform selected activities independently at home and asked to record the frequency with which they complied. The range of motion of the patients' joints were measured before and after rehabilitation.

Variations in compliance occurred in response to life events and the evolving status of the injured limb. The incidence of overcompliance, and the high levels of compliance reported, exceeded expectations. Some low rates of compliance were reported but only as brief incidents. The relationship between compliance with prescibed home program activities and gains in joint mobility needs further study. 


\section{ACKNOWLEDGEMENTS}

It is a great pleasure to express my sincere thanks to charles Brown, OTR, CHT, my employer and friend, without whose generous cooperation, and unfailling support this study could not have been conducted. Thanks are also due to Virginia willis for her skillful proofreading, and to Connie Brown for her encouragement and skill at adjusting the work schedule to provide me with extra time for writing.

I am grateful for the unerring guidance of $\mathrm{Dr}$. Lela Llorens in steering this stumbling venture through a thicket of obstacles, many of my own making. My heartfelt thanks go to Dr. Gordon Burton, without whom I would have given up. My thanks also to Mary Kasch for the time she gave as a reader and for her expert suggestions.

I also thank the anonymous volunteers who were the subjects of this study. Without their cooperation there would have been no data about which to write. 
TABLE OF CONTENTS

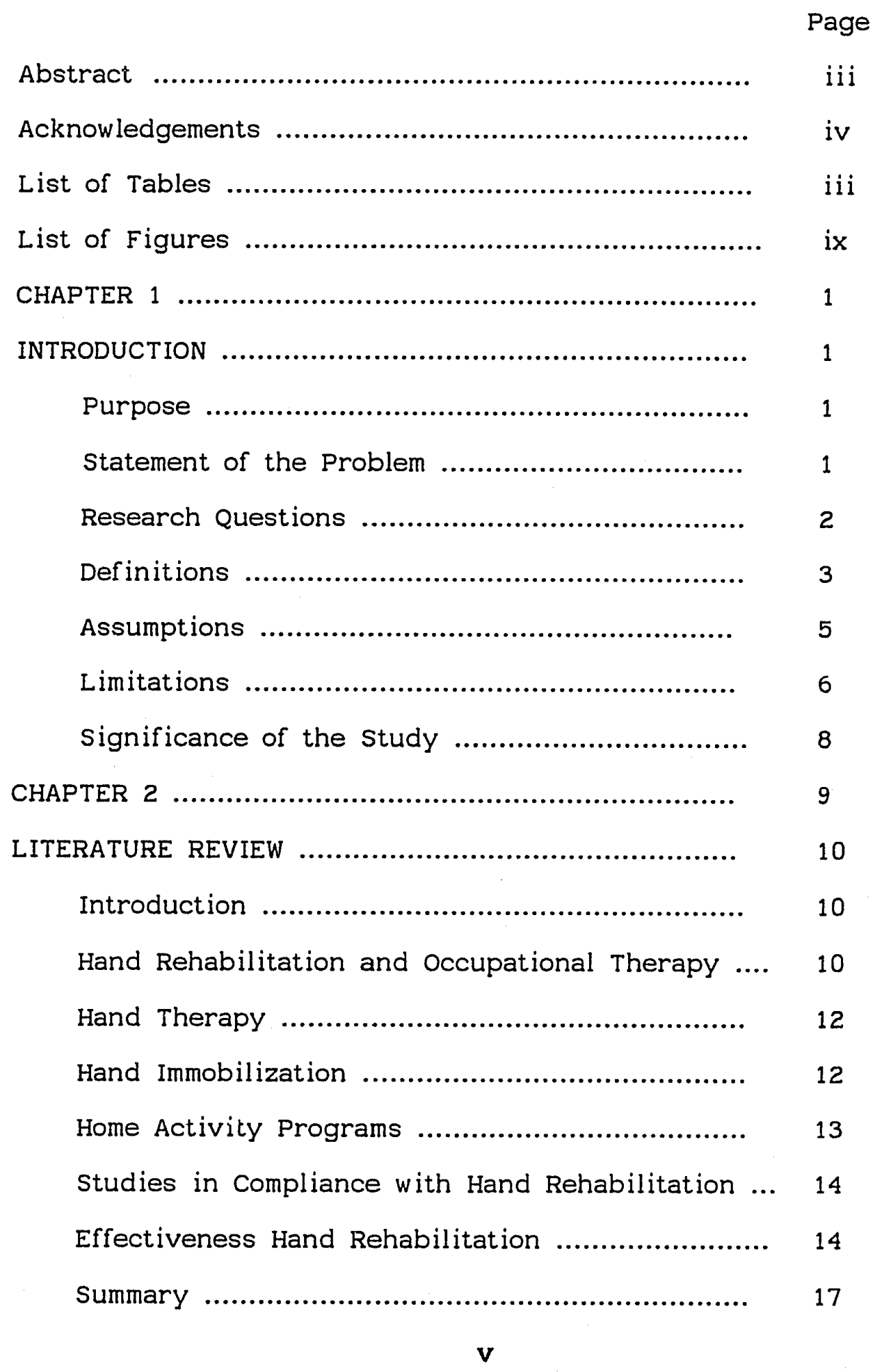


CHAPTER 3 .................................................. 19

DESIGN AND METHODOLOGY ................................. 19

Research Questions ................................. 19

Research Procedures ...................................... 20

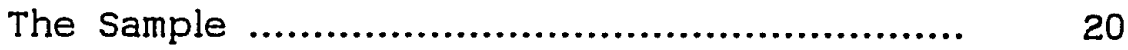

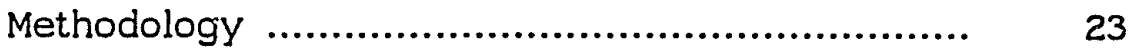

Data Collection Procedures ........................... 23

Data Analysis Procedure ............................. 27

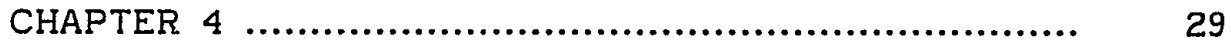

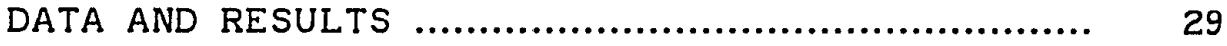

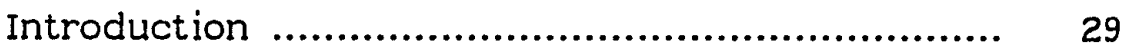

Demographics ............................................ 29

Individual Patient Data ................................ 33

Case Studies ........................................... 33

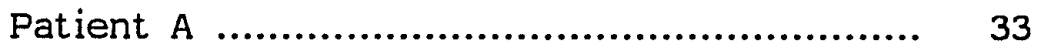

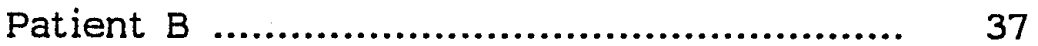

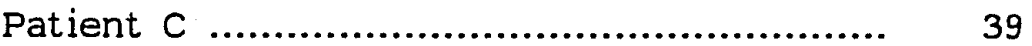

Patient $D$.............................................. 42

Patient E ......................................... 44

Patient $F$....................................... 47

Patient $G$........................................... 48

Patient $\mathrm{H}$..................................... 50

Activity Use Data ...................................... 51

Grip Strength Data .................................... 65 


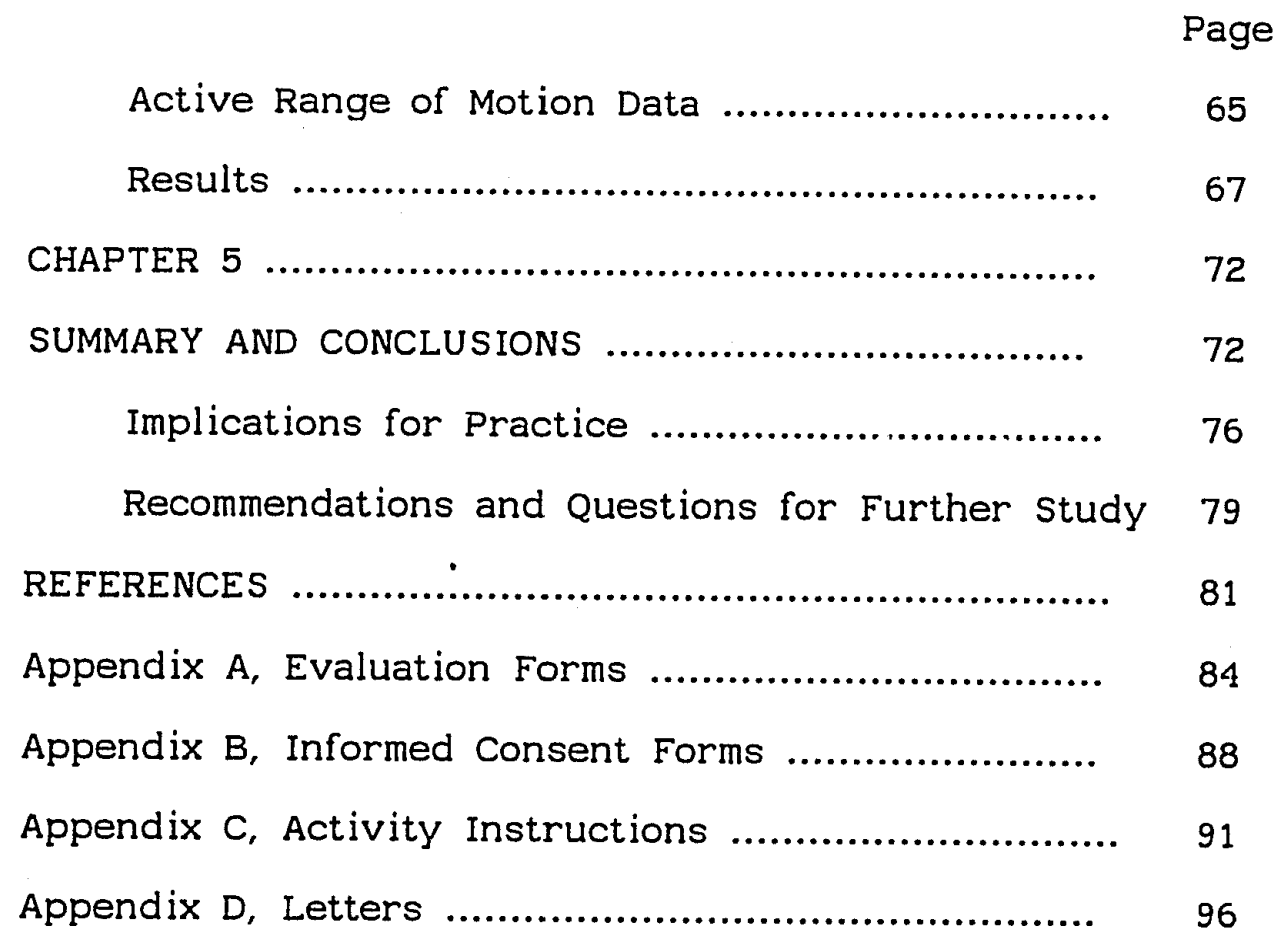




\section{List of Tables}

Page

Table 1, Demographic Profile of Patient Subjects ................. 32

Table 2, Average Percent of Compliance with the Activities Prescribed for their Home Programs by All Patient ... 62

Table 3, Grip Strength Prior and Post Treatment ................... 66

Table 4, Degrees of AROM at the Wrist and Forearm ............ 68

Table 5, Mobility Gains Compared with compliance ................. 70 


\section{List of Figures}

Page

Figure 1, Patient A: Recorded Activity Use and Pain Levels 54

Figure 2, Patient A: Recorded Activity Use and Pain Levels 55

Figure 3, Patient A: Recorded Activity Use and Pain Levels 56

Figure 4, Patient A: Recorded Activity Use and Pain Levels 57

Figure 5, Patient A: Recorded Activity Use and Pain Levels 58

Figure 6, Patient A: Recorded Activity Use and Pain Levels 59

Figure 7, Patient A: Recorded Activity Use and Pain Levels 60

Figure 8, Patient A: Recorded Activity Use and Pain Levels 61

Figure 9, Patients' Compliance with their Recommended Home Activity Programs $\quad 63$

Figure 10, Patients' Rate of Compliance with Each Activity 64 


\section{CHAPTER 1}

\section{INTRODUCTION}

\section{Purpose}

The purpose of this study was to determine the frequency with which outpatients who received occupational therapy for upper extremity rehabilitation complied with the recommended frequency for use of activities in their home activity programs and to explore the relationship between the use of eight prescribed activities and recovery of active range of motion.

\section{Statement of the Problem}

Occupational therapists who specialize in providing hand rehabilitation frequently recommend activity programs to be performed by their patients at home. The healing of an injured limb proceeds around the clock, progressing through sequential stages that present windows of opportunity to combat the deleterious effects of inactivity: edema, tissue shortening, fibrosis, and muscle atrophy. Overcoming the joint stiffness and loss of strength which usually follow trauma and immobilization requires frequent daily repetition of therapeutic activities. The two to four hours a week in which outpatients with hand injuries perform activities under the supervision of an occupational therapist are too few to assure optimum rehabilitation. Even if the frequency and duration of therapy sessions were not limited by the physician's prescription, payment constraints or the difficulty that some 
patients have in obtaining transportation to therapy, for instance, it would be necessary for most patients to engage in therapeutic activities independently. A home activity program is a readily available, cost-effective means of amplifying the benefits of supervised therapy. However, the problem of patients' compliance with home activity programs needs to be studied further.

In order to begin to establish a knowledge base concerning activities performed independently by patients, it is important to document the relationship between activity prescription by the therapist and activity use by the patient. The relationship between activity use and regained skills also needs to be documented. This study was designed to begin this documentation.

\section{Research Questions}

The questions generated for this study were:

1) What is the frequency of compliance with each of the activities in a recommended home activity program reported by outpatients with upper extremity joint stiffness that followed immobilization for fractures, contusions, or crush injuries?

2) What is the relationship between gains in active range of motion and the frequency of compliance with one or more recommended home program activities as reported by outpatients with upper extremity joint stiffness that followed immobilization for fractures, contusions, or crush injuries? 


\section{Definitions}

The definitions generated for this study were:

Bilateral: Pertaining to, affecting, or related to two sides;

i.e., right and left hands.

Collagen Alteration: Changes in the structure of scar tissue produced by immobilization or stress; scar remodeling.

Compliance: The act of complying; a yielding, as to a request, wish, desire, demand or proposal.

Contracture: Permanent contraction of a muscle as may result from fibrosis of tissues surrounding a joint.

Contusion: An injury in which the skin is not broken; a bruise.

Crush injury: An injury caused by maximal compression of a body part or impact to the body which results in widespread disruption of tissue. The injury may or may not include bony fractures and laceration of the skin surface.

Distal: Farthest from the center of the body.

Edema: Fluid accumulation in a body tissue; swelling.

Erythema: Redness of the skin.

Fibrocartilage: A type of cartilage containing thick bundles of collagenous fibers.

Fibrosis: Abnormal formation of fibrous tissue; scarring. 
Fixator: A device used to prevent unwanted movement at and/or between anatomical joints. Fixation devices may be external (i.e., casts, splints, or Agee fixators) or internal (i.e., K-wires, rods, plates, and screws).

Fracture: A broken bone.

Ganglion: A mass of nervous tissue composed principally of nerve--cell bodies and lying outside the brain or spinal cord.

Home Activity Program: A group of tasks or exercises selected to supplement and reinforce the activities used by the patients during supervised treatment. A home program is to be used by the patient at home, independently or with the assistance of trained family members.

Immobilization: The prevention of movement of an injured body part by means of a splint, cast or other fixation device (an internal or external fixator).

Jamar Dynamometer: An apparatus used to measure grip strength of the hand.

Ligamentous: Related to a ligament.

Muscular Atrophy: A decrease in size of muscle tissue, especially due to lack of use.

Osteotomy: The operation for cutting through a bone.

Outpatient: A patient who resides at home and comes to a therapy center for treatment.

Proximal: Closest to the center of the body. 
Range of Motion: The arc through which a joint moves. Active range of motion is produced by contraction of the muscles which extend across the joint being moved. Passive range of motion is produced by a force unrelated to the moving joint; i. e., the opposite limb, a splint, or another person.

Stellate Ganglion: A sympathetic ganglion formed by the fusion of inferior cervical and first thoracic ganglions.

Tendinitis: Inflammation of a tendon.

Transcutaneous: Transmitted through the skin.

Trauma: An injury or wound violently produced.

Upper Extremity Joints: Bony articulations of the hand and arm; i.e., the joints of the finger, wrist, elbow, and shoulder.

Venous Stasis: Stagnation of blood in the veins.

\section{Assumptions}

It was assumed that all patients had the potential to achieve increased range of motion in the injured limb, based on the medical information available. The absence of joint fusion was a condition for eligibility.

It was assumed that the activities recommended to the patients were appropriate for remediation of their injury. These were selected by an occupational therapist experienced in hand rehabilitation, based on the skill deficits observed.

It was assumed that the patients reported their use of home program activities honestly and accurately. Dubious data were eliminated. 
It was assumed that the measurements of joint range of motion were accurate. The two therapists involved in the data collection used the same instruments and measuring techniques and served as a check for each other.

\section{Limitations}

The use of self-reports as a method of data collection is a limitation of the study. In the absence of tamper-proof, automatic counting equipment, the extent to which the equipment was used cannot be verified. signs of use, or of misuse, may or may not be evident. Carelessness, faulty memory, and the inclination of patients to exaggerate their performance are drawbacks inherent in any self-report system. Immediate recording at the time of performance has been demonstrated to encourage a higher level of compliance (Nelson, 1977), whereas memory-based reports are less inclined to alter compliance but may be less accurate. The accuracy of either method may be compromised by the patient's desire for therapist approval, although encouraging patients to report as honestly as possible may help to counteract this effect. (Codori, Nannis \& Pack, 1992).

Awareness of the purpose of the study by the primary data collector is a limitation of the study. Use of the double blind method, to prevent contamination of the data by a possibly biased data collector, was not an available option. 
The knowledge by the patients that they were being studied may have induced them to perform better than they would have otherwise. The "Hawthorne Effect" may have occurred (Isaac \& Mitchel, 1981).

The recommendations for activity use were predicated on the patient's observed ability. A limitation for the study is that a therapist's estimate may be faulty, undermined by poor communication, or rendered inaccurate by unforeseen circumstances, therefore, resulting in undercompliance or overcompliance.

Obtaining accurate measurements of active range of motion depends, in part, on the patient's being willing to make a maximal effort during each measurement. The range of motion achievable may also vary with the time of day, the weather, or any activity the patient was engaged in prior to being measured. A limitation of the study is that there was little or no ability to control these variables.

The external validity, or ability to generalize the results of the study, is limited by the sampling technique used and by the small size of the sample obtained. 


\section{Significance of the Study}

Rehabilitation is an interactive process which requires patient involvement and cooperation for success. Regular use of a home program of activities encourages therapeutic movement on a daily basis. It may be crucial to the recovery of lost mobility, but there are obstacles to obtaining patient compliance with such a program.

It would be useful in planning a home program to know if compliance is facilitated by the selection of particular activities. If gains in range of motion can be shown to be related to the use of certain activities, and if increased mobility can be shown to coincide with a greater frequency of compliance with the home activity program, such finding would have implications for professional occupational therapy practice. 


\section{CHAPTER 2}

\section{Literature Review}

Introduction

This chapter reports literature relevant to hand injury and hand rehabilitation, the treatment of hand injuries by occupational therapists using home activity programs, studies on compliance with prescribed independent therapy, and other approaches to hand rehabilitation.

Hand Rehabilitation and Occupational Therapy

A trivial injury can incapacitate a person's hand temporarily (Hardy, 1986). Severe trauma can cause disability that endures for months or years. Many hand rehabilitation patients have discovered Hardy's (1986) observation that "successful healing does not necessarily correlate with return to function. The ability to use our hands requires sensation, mobility, stability, and freedom from disabling pain or anxiety" (p. 1).

Occupational therapists who specialize in hand rehabilitation seek to enable patients to achieve maximum adaptation to the demands of their personal activities of daily living when injury or disease impedes the spontaneous, reliable use of the hands (Cromwell \& Bear-Lehman, 1988). Harvey and Morey (1986) cited patient motivation, recovery of active and passive range of motion, and improvement of strength and functional dexterity as important factors leading to recovery of hand function. Hand rehabilitation 
patients of ten express frustration with their inability to perform learned skills and are impatient with their rate of recovery. Patients are usually eager to return to their jobs, get out on the golf course, or enjoy the simple pleasure of cutting up their meat, but are stymied by a hand that will not cooperate - a hand that they are sometimes afraid to use (McEntee, 1990). Occupational therapy provides a supportive environment in which to renew and acquire skills. Jane Bear-Lehman (1983), in a study of factors affecting patients' ability to return to work, concluded that the socio-psychological support provided by occupational therapists may be more influential than is generally realised.

A resolution adopted by the American Occupational Therapy Association in 1979 states, in part:

Occupational therapy is based on the belief that purposeful activity (occupation, including its interpersonal and environmental components) may be used to prevent dysfunction, restore functional ability, and facilitate maximal adaptation to impairment.

According to Melvin (1985):

The philosophical base of occupational therapy is consistent with the total concept of care necessary to help an individual with hand dysfunction to resume a meaningful, productive role in society. The emphasis of occupational therapy on function, work, purposeful activity, and adaptation is critical to an individual trying to overcome the limitations of a severe hand 
injury or impairment. (pp. 795-796)

Pedretti and Pasquinelli (1990) stated, "the concerns of occupational therapy are the performance skills (self-care, work, education, and play and leisure activities) and the performance components which are the substructure of the performance skills" (p. 2). The occupational performance frame of reference, modeled in "A Curriculum Guide for Occupational Therapy Educators" (AOTA 1974) and elaborated by Mosey (1981) and Pedretti and Pasquinelli (1990), is as appropriate to hand rehabilitation as it is to other forms of physical disability. Assessment and treatment of deficits in the motor functioning performance component (range of motion, gross muscle strength, muscle tone, functional use, gross and fine motor skills) are important steps in hand therapy. The sensory, cognitive, psychological, and social components of behavior also require attention if the patient is to be successfully rehabilitated.

The usual course of clinical treatment in hand rehabilitation closely parallels the treatment continuum, described by Pedretti and Pasquinelli (1990), in which adjunctive methods facilitate the use of enabling activities which prepare the patient to perform the functional activities of daily life. In the occupational performance model, home program activities would equate with the enabling activities used prior to, or in conjunction with, more intrinsically purposeful activities. The activities recommended for home programs are designed to provide repetitive practice of impaired hand skills at a level consistent with the patient's capability. They 
are valuable to the degree that they enable the patient to advance to the final stage of treatment: occupational performance and community reintegration. The goal of treatment in the occupational performance model, as it is in hand rehabilitation, is independence in self-care and the resumption of former roles and occupations to the maximum extent possible for each patient.

\section{Hand Therapy}

Hand Immobilization

In the absence of movement, joint stiffness and muscle atrophy commence within a week or two. The degree of stiffness and muscle weakness increases with the duration of immobilization (Frykman \& Nelson, 1990). According to Curtis (1990), active movement of the extremities post injury is essential to reduce edema, prevent venous stasis, and ensure adequate nutrition of healing tissues. When immobilized, an injured limb is subject to collagen alteration, fibrosis, and ligamentous shortening. Sorensen (1986) reported that frequent active movement of the joints proximal and distal to a fracture site is critical to maintaining range of movement of the uninjured joints. Frykman and Nelson (1990) have suggested emphasizing the importance of active movement by exaggerating the frequency recommended to patients. They also assert that therapy is essential to mobilize the stiffened wrist and to increase strength and function of the hand and arm after casts or other fixators have been removed. Mackin (1986) stated that 
range of motion exercise is an important part of any hand therapy program. Needless immobilization of uninjured joints should be avoided, and active movement of the uninvolved joints is necessary to preserve their mobility. Joints which become stiffened in a poor position may require months of effort to regain lost range of motion. Early active digital motion discourages adherence of tendons at a fracture site, diminishes edema by pumping fluid from the fingers, and decreases ligament contracture. Mackin has cautioned against excessive exercise or passive movement applied too aggressively which may increase inflammation of injured tissues, leading to increased fibrosis and further loss of mobility.

\section{Home Activity Programs}

Enlisting active patient participation in occupations is crucial to achieving an optimal therapeutic outcome. Pain and fear of re-injury often discourage patients from engaging in active movement and may inhibit the resumption of life skills (McEntee, 1990). According to Murphy (1987), when therapists urge, cajole, and nag their rehabilitation patients into further accomplishment, patients become very much involved in their own recovery. The treatment of severe hand injury, edema control, scar remodeling, tendon gliding, and joint mobilization techniques requires a daily program. A specifically designed home program, carried out by the patient (possibly with the help of family members), is essential. The patient, and any assistants, must be trained to perform these 
activities correctly (Melvin, 1985). Reporting the case history of a crush injury to the hand, McGee-Johnson (1988) also emphasized the importance of patient involvement and the need to educate the patient and others in home program activities.

\section{Studies of Compliance with Hand Rehabilitation}

Codori, Nannis and Pack (1992) stated that "noncompliance is pervasive; patients are not apt to report spontaneously their compliance lapses; and therapists cannot be effective without their patients' cooperation." The issue of patient noncompliance has been studied in several contexts: for instance, patient cooperation with an ulcer diet (Caron \& Roth, 1971), the use of resting splints by arthritis patients (Feinberg \& Brandt, 1981), and home program compliance by juvenile rheumatoid arthritis patients (Wynn \& Eckel, 1986).

An exploratory study of compliance with home exercises was conducted by Codori, Nannis and Pack (1992) with 61 patients with hand injuries at a Baltimore hand therapy center. The patients were asked to report their use of prescribed activities based on memory, following which their proficiency in performing the activities was assessed by therapists who were naive as to the purposes of the study. Codori et al. (1992) hypothesized that self-reported exercise compliance would correlate positively with exercise proficiency. It was found that greater compliance was associated with greater proficiency. 
Each of the available methods of self-report, reports based on memory and reports based on daily recording as the activities occur, have advantages and disadvantages. Although recording at the time of performance has been demonstrated to encourage a higher level of compliance (Nelson, 1977), it was decided to use this method becaluse it relies less on accurate memory. The accuracy of either method may be compromised by a desire for therapist approval. Encouraging patients to report as honestly as possible may help to counteract this effect (Codori, Nannis \& Pack, 1991).

Several means of encouraging compliance have been suggested. Salter (1987) described several game adaptations which were used to encourage specific movements but reported that, while they are useful, in a prolonged treatment regime games become as repetitious as exercises. McGee-Johnson (1988) recommended varying the activities to provide continued challenge and prevent boredom. Hardy (1987) cautioned that trying to accomplish too many things at once may overwhelm the patient and result in poor compliance.

\section{Effectiveness of Hand Rehabilitation}

Since many diverse factors affect upper extremity function, including anatomical integrity, mobility, strength, sensation, coordination, age, sex, mental state, and diseases that involve other areas of the body (Jebsen, Taylor, Treischmann, Trotter \& Howard, 1969), measurements of strength, range of motion, and volume may be of dubious value in predicting functional ability. They do, however, give an indication of a patient's ability to perform with 
his/her hands (Carol, 1964). A better predictor of function may be found in one of several tests designed to measure functional ability: the Jebsen-Taylor Hand Function Test (Jebsen et al., 1969), consisting of seven subtests representative of everyday functional activities; the Smith Hand Function Evaluation (Smith, 1974), a four-part test with several subsections; and the Klein-Bell ADL Scale (Klein \& Bell, 1982), which rates patient performance of 107 activities of daily living ( $A D L$ ). Administration of the Smith test to normal subjects reportedly requires approximately 20 minutes, but a subject with an impaired hand may need 45 to 60 minutes or more to complete the test (Smith, 1974). The Jebsen Hand Function test is time-limited and requires about 30 minutes to complete; however, Lynch and Bridle (1989) judged the Jebsen-Taylor test to be only "somewhat useful for predictions of functional hand use in activities of daily living" compared to the Klein-Bell, which is more comprehensive and takes much longer to complete. These tests facilitate comparisons of function between patients (pre-treatment and post-treatment) or with a standard rating scale. The problem with utilizing multi-part activity tests is finding the time required to administer them within the constraints of authorized treatment time.

To evaluate the effectiveness of treatment, Hardy (1986) recommended choosing an objective parameter appropriate to the structure being treated, such as passive joint motion for joint capsule tightness, and comparing initial measurements with 
subsequent measurements. If no change is evident in a short time, then the treatment plan must be revised. Comparative measurements of joint range of motion, circumference or volume, grip and pinch strength, and sensibility tests are standard performance evaluations included in hand therapy progress reports.

Ultimately, hand function is demonstrated by a patient's ability to resume his or her career, enjoy his or her hobbies, and carry out personal care functions (Hardy, 1986). Cromwell and Flinn-Wagner (1988) stated that a patient's satisfaction with hand therapy tends to be based on the restoration of function, purpose, and the ability to resume vocational and avocational pursuits.

\section{Summary}

As reported in the literature, the philosophical base of occupational therapy is well suited to the practice of hand rehabilitation. The occupational performance frame of reference described by Pedretti and Pasquinelli (1990) delineates and supports the methods and approaches used by occupational therapists in the treatment of patients with hand injuries.

It has been found that the undesired side effects of prolonged immobilization can be counteracted by active daily movement of an injured limb. Involvement of the patient in therapeutic activities, both under supervision and independently at home, has been reported to be an essential aspect of treatment. 
Studies of patient compliance have indicated that patient noncompliance is frequent. Self-report is a means that has been used to collect data on home program compliance. The self-reported data were verified by assessment of the patients' proficiency in the performance of the home program exercises.

It has been stated in the literature that objective measurements can be used to assess the effectiveness of treatment. While measurements of physical capacity do not equate with functional ability, they have been found to indicate functional potential. It has been reported that the ultimate measure of rehabilitation is the ability of the patient to resume self-care, work, and leisure activities. 


\section{CHAPTER 3}

\section{DESIGN AND METHODOLOGY}

This investigation used a multiple case study design to determine the frequency with which outpatients who received occupational therapy for upper extremity rehabilitation complied with the recommended frequency for use of activities in their home activity programs and to explore the relationship between the use of eight prescribed activities and recovery of active range of motion.

\section{Research Questions}

The questions generated for this study were:

1) What is the frequency of compliance with each of the activities in a recommended home activity program reported by outpatients with upper extremity joint stiffness that followed immobilization for fractures, contusions, or crush injuries?

2) What is the relationship between gains in active range of motion and the frequency of compliance with one or more recommended home program activities as reported by outpatients with upper extremity joint stiffness that followed immobilization for fractures, contusions, or crush injuries? 


\section{Research Procedures}

The following procedures were followed for this study:

1) Data were collected over a finite period of 33 weeks, from June 19, 1992, to February 5, 1993.

2) The patient subjects were seen primarily by one therapist for time period of therapy.

3) The data were collected and documented by initial evaluation report, interim and final progress reports, and daily treatment notes.

4) Treatment was individualized for each patient, predicated on the physician's recommendations and the treating therapist's assessment of the patient's rehabilitation needs.

\section{The Sample}

Patients were invited to participate in the study from the clientele of the Hand/Arm Therapy Center, referred to hereafter as the Center. It is a small, privately owned facility in Yuba City, California. The patients were volunteers who were referred to the Center by their physicians or surgeons for hand rehabilitation following trauma and/or surgery to the wrist or forearm. All patients who qualified were enrolled as study subjects. Subjects received the same type of therapy as other patients with similar conditions. The only respect in which these patients were treated differently was that they were requested to record their use of the activities in their home activity programs. 
An initial evaluation was performed on all potential subjects. Each patient's age, sex, vocation, dominant hand, injured hand, referring diagnosis, and date of injury and/or surgery was documented. The location and status of any wounds were recorded. Range of motion at the wrist, forearm, elbow, and shoulder was measured bilaterally. If hand closure was impaired, the range of motion of finger and thumb joints was also measured. Edema was assessed by observation, circumferential measurements, and/or volumetric measurement of the hand and distal forearm, bilaterally. Bilateral grip strength was measured using a Jamar dynamometer (whenever possible). The patient was queried about how the injury occurred, how it had been treated, how long the cast or external fixator had been worn, and when the cast or fixator had been removed. Patients were asked to describe how their injuries were limiting their present functional abilities. The injured limb was examined for pain and sensibility, and the location and nature of any distortions was noted. A sample of the initial evaluation form can be found in Appendix $A$.

Based on the evaluation, a treatment plan was prepared'and the goals of treatment were determined. When the initial evaluation was concluded, and if the patient appeared to be a suitable candidate for the study, he or she was asked to participate, usually near the end of the first visit. Patients who indicated an interest in joining the study group were presented with a consent form (see 
Appendix B). When the form had been read, any questions had been answered, and the investigator was satisfied that the patient understood the request, the patient was asked to sign the form.

Eligibility for the study required meeting all six of the following criteria:

1) The patient had incurred a fracture of the wrist and/or forearm, or a severe contusion or crush injury for which immobilization was required.

2) The injury had required immobilization of the wrist and forearm in a cast or by other stabilizing fixators (internal or external) for two (or more) consecutive weeks.

3) All external fixation devices had been removed and the injury was sufficiently healed to permit active movement of the injured limb. The presence of internal fixators that did not cross a joint was acceptable.

4) The patient's range of motion at the wrist and forearm of the injured extremity was less than normal (by comparison with the opposite limb). Impaired mobility at other upper extremity joints was acceptable, but adequate gross grasp and grip strength (immediately or soon after starting therapy) was required to enable the patient to hold the equipment used in performing the activities under study.

5) The patient had the potential to increase range of motion of the injured wrist and forearm by means of therapy and the range of motion of the opposite wrist and forearm were within 
normal limits. Patients who had sustained surgical fusion of the injured wrist or permanent loss of mobility in the opposite wrist or forearm were excluded.

6) The therapist had obtained informed consent by the patient and the consent of the referring physician.

Thirteen patients were invited to participate and were enrolled in the study. Data were collected on the ten patients who remained enrolled.

\section{Methodology}

\section{Data Collection Procedures}

The patients were educated in the use of three or more of eight activities commonly used at the Center to treat the effects of the types of injury which rendered the patients eligible for the study. These activities, described and illustrated in Appendix C., were:

1) The wrist roller activity.

2) A unilateral wrist ranging activity.

3) A bilateral wrist ranging activity.

4) The metronome (or wand) activity.

5) The broomstick activity.

6) The finger-in-ear activity.

7) The Dexterciser II activity.

8) The beach ball rolling activity. 
Three to six (usually four) of these activities were included in a patient's home program at one time. A schedule of use was recommended based on the patient's capacity for activity as observed during treatment. Patients were provided with any equipment needed to repeat the selected activities at home. Other activities which were not under study, such as putty squeezing and foil ball rolling, were also recommended for home use when appropriate for the patient's needs. The patients were not required to record the use of these activities.

Each subject patient was provided with a home program activity booklet, the cover of which was inscribed with the patient's name and the date of issuance. The booklets contained illustrated instructions for each of the prescribed activities, score sheets, and general instructions on how to use the score sheets to record activity use and discomfort scale estimates. These were fastened together with brass paper fasteners in order to permit additions and deletions to the activity booklets. Use of the score sheets and the discomfort scale was explained and demonstrated. Patients were requested to estimate their discomfort while performing each activity by selecting a number from 1 to 10 (where 1 was equal to no pain and 10 equalled extreme pain) and record it on the score sheet for that activity. The booklet covers, general instructions, and a sample score sheet can be found in Appendix $\mathrm{C}$. 
The importance of honest and accurate recording of activity use was emphasized to all patients when they received their program booklets. This was reiterated when new activities were added to the programs.

As a part of therapy, the patients' proficiency in performing home program activities was assessed frequently, and additional instruction or activity modification was provided as needed. As recovery progressed, the level of difficulty of the activities was increased. This was accomplished by recommending more frequent repetition, adding an element of resistance, or by replacing one activity with another. Activities were chosen to counteract whichever movement impairments seemed most troublesome at that time. Activities requiring supination, for instance, would be prescribed for a patient complaining of difficulty turning doorknobs. All eight activities were not equally suitable for all patients and were not used by every subject.

The patients were asked to report verbally on their home program use in the same manner as nonsubject patients. If problems with compliance were reported or signs of overuse noted (increased pain, edema, or stiffness), the program was adjusted to accommodate these conditions and the reasons for noncompliance were recorded in the daily notes. Patients were requested to bring their booklets to therapy only when additional score sheets were needed or other activities were to be added to their program. The patients surrendered their home program booklets when their 
therapy was completed. At the time the study ended it was necessary to collect the booklets from three patients before their therapy had been completed.

A complete set of range of motion measurements (and other objective measurements made at the initial evaluation) was repeated periodically during the course of therapy in the form of progress reports (see Appendix A). The preparation of progress reports at the Center is arranged to coincide with each patient's medical appointment schedule in order to provide the doctor with a current evaluation of the patient's status. The range of motion of one or more joints was also measured at variable intervals between medical appointments to assess the effect of treatment. These measurements were recorded in the daily notes.

The treatment of study subjects was assigned to the therapist/investigator whenever possible, but when the therapist/investigator was not available, subjects were seen by one other therapist. Measurements were made by both practitioners during the course of the study. Although no formal test was conducted, there is reason to believe that there was a high degree of inter-rater reliability. Both therapists employ the same tools and techniques since the therapist/investigator was trained in hand therapy methods by the other therapist. In addition, other than study subjects, any given patient may, on occasion, be seen by the other therapist; thus consistency of technique is an ongoing concern. 


\section{Data Analysis Procedure}

The comparable group data obtained in this study are of two types: the reported frequency with which prescribed activities were performed by the patients in relation to the number of times activity performance was recommended (the percentage of compliance), and the changes in active range of motion of the patients' impaired upper extremity joints before and after treatment.

Detailed information specific to each patient throughout the course of their therapy is presented in the form of case histories. The events or conditions that affected compliance adversely (i.e., bumps, falls, work or social commitments) are described and related to activity compliance at the time of the occurrence.

Sequential overlaid bar graphs were used to provide an overview of each patient's compliance with his or her prescribed home program activities. The patients' estimates of discomfort while using the activities were shown below the bars to indicate the influence of pain on activity performance.

since each patient followed an individualized program, the recommended frequency of use differed from one patient to another and changed over time for the same person. Comparison of the actual number of repetitions performed by each patient would be meaningless. The percentage of compliance was used to permit comparisons between the patients' performances. 
In these patients, the wrist and forearm joints were the most impaired initially and were therefore the joints most inclined to gain degrees of motion. Active range of motion (AROM) of the elbow and/or shoulder is included in the results only for patients in whom these measurements changed markedly.

Bar graphs were used to show the comparative compliance with their total home activity programs by all the patients and to illustrate the patients' comparative compliance with the eight activities under study. 


\section{CHAPTER 4}

\section{Vata and Results}

Introduction

This study investigated the use of home program activities by patients who received occupational therapy for hand rehabilitation and the relationship between patient compliance with home program activities and gains in active range of motion. Eight patients completed the study. Their use of home program activities, their reactions to treatment, and the changes that occurred in their upper extremity mobility are described in individual case studies. Individual and group data are presented as tables and graphs to facilitate comparisons between the performance of individuals and to illustrate the performance of the group as a whole.

\section{Demographics}

The eight subjects were patients referred by local physicians to the Hand/Arm Therapy Center of Yuba City, California, for upper extremity rehabilitation. The twin cities of Yuba city and Marysville, located in the Sacramento valley 50 miles north of Sacramento, have a combined population of approximately 30,000 people. These small cities are surrounded by orchards, farm land, and rural foothills. The patients who come to the Center, from up to 50 miles distant, are employed in a variety of white-collar and blue-collar occupations, such as office worker, gold miner, oil 
driller, bus driver, farm laborer, mill hand, teacher, mechanic, retail clerk, and farmer. Some of these are represented in the sample group.

Thirteen patients were originally enrolled in the study. One explicitly withdrew before reporting any use of home program activities. Two others withdrew by default when they failed to return for therapy after one or two treatments. Of these, one reported that his return to work (after a two week vacation) left him too little time for therapy and that he had lost his activity booklet while on vacation. The other, an 80-year-old, stated that she was unable to continue therapy because going out in bad weather made her arthritis worse.

Two patients were subsequently eliminated from the study because the data they submitted were either insufficient or suspect. One of these had attended therapy only a few times before leaving on a two-week vacation. Upon her return, she failed to keep two successive appointments. She was informed that she could not resume therapy without a new prescription from her physician, which evidently was not obtained. Her activity booklet, when it was returned, indicated that she had recorded her home activity program use at an excessive rate and for only seven days. The other patient attended therapy three times a week for four weeks, during which time he did not remember to bring his activity booklet 
with him. He stated that he was doing the activities but avoided mentioning how frequently. Throughout his therapy he had complained of severe pain, both with and without movement; but his activity record, when received, omitted any reference to pain and indicated extreme overuse of all activities, up to $182 \%$ more than had been recommended. After four weeks of treatment, he unexpectedly announced that his pain was gone and he was ready to return to work. The therapist recommended discontinuing therapy and his physician concurred. It was believed that the data generated by these subjects were inadequate and dubious and should not be retained.

The eight remaining patients, five men and three women, ranged in age from 34 to 68 years, with a mean age of 52. of the men, three had worked full time until they were injured, one as a police officer, one as a farm worker, and one as a bus driver. One man had retired from construction work and was about to begin a new career as a building inspector. The fifth man was also retired and built boats as his avocation. Among the three women there was a homemaker, a medical transcriptionist, and a school testing specialist (see Table 1). All eight patients had sustained fractures of the radius or radial and ulnar bones of the forearm. Their injured limbs had been immobilized for six to eight weeks following their accident or after corrective surgery performed subsequent to the healing of the original injury. No patients with crush or contusion injuries were available for the study. 
Table 1.

Demographic Profile of Patient subjects $\quad(N=8)$

\begin{tabular}{cllll}
\hline Subject & Gender & Age & Occupation & Referring Diagnosis \\
A & Male & 47 & Police officer & Right ulnar osteotomy \\
B & Male & 68 & Retired & Left forearm fracture \\
C & Male & 45 & Farm worker & Right radial osteotomy \\
D & Male & 63 & Retired & Left arthroplasty \\
E & Female & 54 & Homemaker & Right distal radial fracture \\
F & Female & 68 & Test specialist & Right distal radial fracture \\
G & Female & 34 & Transcriptionist & Right distal radial fracture \\
H & Male & 34 & Bus driver & Right distal radial fracture \\
\hline
\end{tabular}


The eight patients were all right-hand dominant. Six had injured their dominant hand; two had injured their nondominant hand. The interval since the original injury ranged from eight weeks to more than a year. At the time the patients were enrolled in the study six to fifteen weeks had elapsed since their injury or their most recent surgery. All casts and external fixators had been removed and the patients' physicians had indicated that active movement was appropriate. The period of patient participation in the study ranged from four to twenty-one weeks.

\section{Individual Patient Data}

An individualized treatment plan was developed to meet the needs of each patient. The treatment which was provided to patients during the term of the study included development of a home activity program and the provision of a home program activity booklet (See Activity Instructions in Appendix C). The response of each patient to therapy, the use of home program activities, and the circumstances that influenced compliance with home program activities, is described in the case studies.

\section{Case Studies}

\section{Patient $\mathrm{A}$}

This 47-year-old male, a police officer, was involved on the job in an automobile accident in which he sustained multiple injuries to his right dominant hand, which included fracture of the distal forearm and a torn triangular fibrocartilage in the wrist. Six 
months after the original injury, surgery was performed to shorten the ulnar bone of the forearm. This bone was reinforced with a plate and screws. After being immobilized in a cast for several weeks, he was referred to the center for hand therapy. When first seen, the patient was wearing rigid wrist support, tightly wrapped. He stated that this helped to control the pain in his wrist. The surgical wound was healed and the wrist was swollen, stiff, and painful to move. He could not grasp firmly enough to register any measurable grip strength.

The patient was instructed in the use of edema control techniques and mobilizing activities, Numbers $2,3,5,6, \& 7$ in the Home Activity Program Booklet (Appendix $C$ ) and was urged to reduce his use of the wrist support as tolerable. He was invited to join the study, to which he consented. In the first week he complained of a constant ache in his forearm and wrist, placing his pain level at four on a scale of one to ten (4/10) when inactive, and up to $9 / 10$ when actively moving. In the second week of treatment he reported that his arm felt better and that he was wearing the wrist support less often. He was issued exercise putty to use at home along with other activities. Toward the end of the second week, the patient complained that his arm was aching more at night, but not intolerably. This declined in the third and fourth weeks of treatment. By the end of the first month, the patient had made excellent gains in active range of motion (AROM) and grip strength. His self-record showed a rate of compliance with his home program activities ranging from $80 \%$ to $97 \%$ and steadily declining pain 
levels. Progress continued into the fifth and sixth weeks, after which time the patient returned to work, limited to office duty. Although the patient continued to use the home activity program in the sixth and seventh weeks, no activity use was recorded because the patient had filled his score sheets and had not requested additional forms. A week after returning to work he stated that his arm was sore because he had repeatedly bumped it against his desk. He also complained of the onset of erratic "shooting pains" at the right wrist. A change of activities was suggested. It was when he produced his booklet for activities to be added that the two week gap in the activity record was discovered. In the eighth week of treatment, Activities 3 and 7 were continued but numbers 2, 5 , and 6 were replaced by 1 and 4. Despite these new pains, which occurred in a series and with or without movement, forearm edema decreased and the patient continued to gain in strength and AROM. The patient's surgeon later suggested that irritation by the internal fixation plate could be the cause of these pains but said that the plate could not be removed for 18 months. These sudden, unpredictable pains, which were very distressing to the patient, continued throughout his therapy, eventually diminishing in frequency and severity. Compliance with the new home program rose from an average of $61 \%$ in the eighth week to $80 \%$ in the ninth, and the patient reported experiencing the shooting pains less frequently. Activity 2 was resumed in the tenth week and Activity 3 was discontinued. The patient reported becoming more active at 
home even though using a hammer was painful. The level of difficulty of his home program activities was increased as the competence of his injured hand improved. Compliance with the home program rose to an average of $93 \%$ in the eleventh week. In the twelfth week the patient reported increased pain during therapy (although not in his home program booklet), and signs of increased inflammatory reaction appeared. At the end of the twelfth week the patient's therapy was put on hold for two weeks and he was told to discontinue home program activities temporarily. In the fourteenth week treatment was resumed, and a home activity program consisting of Activities 1, 2, 3, and 7 was instituted. The patient continued to have some shooting pains and some aching, but at a decreased level. In the fifteenth week the patient began using transcutaneous electrical nerve stimulation (TENS) for pain relief during and after activity use. His grip strength and functional ability slowly improved over the next four weeks, and both the constant ache and shooting pains gradually decreased. The patient's home program compliance during this period ranged from a weekly average of $59 \%$, occasioned by an out-of-town trip, to a high of $94 \%$ when he was at home. His self-report indicated declining pain during activity use. In his therapy sessions and by report of self-selected home activities, he demonstrated continuing improvement in functional ability. In the eighteenth week, Activities 1 and 2 were discontinued and 4 was resumed. Compliance with Activities 3 and 4 was reported to be $100 \%$ and $103 \%$. Compliance 
with Activity 7 dropped to zero for ten days while the patient went deer hunting and could not carry the necessary equipment. By the middle of the twenty-first week of treatment, the patient had regained $100 \%$ of normal wrist flexion/extension, $61 \%$ of normal radial/ulnar deviation, and $93 \%$ of normal forearm rotation. Grip strength in the right dominant hand had increased to $83 \%$ of that in the left. Pain during all home program activities had decreased to less than $3 / 10$. The unpredictable shooting pains continued to occur, but less frequently. Because of the high level of physical competence required by his job, he continued to be assigned to office work. He expressed frustration at his inability to resume regular patrol duties. A progress report written at that time stated that the status of the right extremity appeared to have stabilized at a functional level, but the report suggested continuing therapy to address pain in the left arm, possibly due to incipient tendinitis. The physician did not concur; therefore, treatment was discontinued.

\section{Patient B}

This 68 year old male fell in his garden, striking his left arm against a brick planter. His forearm was fractured in the fall and was immobilized in a cast for six weeks. The cast had been removed the day before he was first seen at the Center. The patient was wearing a rigid wrist support, and his wrist and forearm were stiff and swollen. He was instructed in edema control measures and 
provided with home activity program instruction, using Activities 1, $2,3,4$, and 7 . His hand closure was fair, but he was unable to exert measurable pressure on the dynamometer. Exercise putty was issued, and he was instructed in its use. His major complaints at the start of therapy were his inability to turn doorknobs or lift anything. When invited to participate in the study, he consented. He then announced that he was going out of town for a week. The patient had agreed to do the home program activities while he was away, but on his return he indicated that he had been too busy to do any of them. Beginning study participation with a week of complete noncompliance lowered his average compliance rate with all activities and may also have slowed his recovery. From the time he returned, however, he reported performing his activities with a regularity that would have resulted in a very high rate of compliance except that he reported use of only one home program activity on sundays. He made good progress in mobility at the wrist and forearm, but the fingers of his left hand remained stiff and his grasp weak. He complained of pain at the base of his thumb initially. To promote better hand closure, the patient was instructed to wrap his partially closed fist with elastic bandage for gradually increasing periods (up to an hour). This temporarily increased the pain in his hand, but pain during activity use was not major and gradually subsided. He reported improved function in self-selected home activities each week. At the end of the fourth week of treatment the patient had regained $79 \%$ of normal wrist 
flexion/extension, $54 \%$ of normal radial/ulnar deviation, and $96 \%$ of normal forearm rotation. His left hand grip strength had increased from 0 to 31 pounds, $34 \%$ of the dominant right hand grip strength. It was suggested that hand therapy be continued until hand closure and grip strength improved. The physician did not concur, and therapy was discontinued.

\section{Patient $\mathrm{C}$}

This right-hand dominant, 45-year-old male farm worker fractured his left distal radius when he fell off a ladder while pruning a fruit tree. Nine months later a radial osteotomy was performed. Eight weeks later, when the cast had been removed, he was referred to the Center for hand therapy. When first seen, the patient was wearing a rigid wrist support. He appeared to be very protective of the left arm and resistant to moving it. His hand closure was good, but his grasp was weak (six pounds) and painful. His left wrist and forearm were extremely stiff. The patient indicated that he experienced severe pain on movement, not only at the wrist and forearm, but at the shoulder and elbow also. AROM of the elbow and shoulder joints was within normal limits. He was instructed in wrist ranging exercises and issued exercise putty, with instructions for its use. The patient's English-speaking son acted as interpreter, as the patient spoke only in Spanish. It became evident later that he understood English fairly well and could speak it somewhat haltingly. He was invited, through the interpreter, to participate in the study. It was suggested that he 
take the informed consent letter home to study it and think it over. At the third visit he indicated he was willing to participate, and he was able to satisfy the investigator that he understood the nature of the study and was able to give informed consent.

The patient's initial home activity program consisted of Activities 2, 4 and 8 . He continued using these for $41 / 2$ weeks. His AROM increased slowly. In the second week, the patient indicated that his arm was feeling better, but he continued to have significant pain on movement. His grip strength increased gradually despite the pain reported when grasping firmly. The patient stated that he was recording his activity use, but he consistently forgot to bring in his booklet until the middle of the fourth week, at which time it was discovered that he had been overusing Activities 4 and 8 by a large margin. He was told to discontinue these activities and to use Activity 5 in their place. In fact, he continued using them for another week. When Activities 1 and 7 were added to his program near the end of the fifth week, he finally stopped using and overusing Numbers 4 and 8 . A progress report written at this time stated that the patient had made good gains in AROM and his grip strength had increased by 31 pounds, but he continued to report severe pain when moving the wrist and forearm to maximum range. The patient's physician indicated that the osteotomy was well healed and authorized the use of TENS to alleviate pain. The patient was instructed to use TENS during activities and for two hours afterward. His home program now contained Activities 1, 5, and 7. 
Compliance was low at first (50\% to $66 \%$ ), but gradually rose to $80 \%$ to $100 \%$ during the next three weeks. The patient began canceling one, or sometimes two, appointments a week due to car trouble. His mobility and strength continued to increase slowly until the seventh week, when they plateaued. Pain on moving the left arm, particularly when grasping and with forearm rotation, continued. Pain at the shoulder and elbow also continued to be a problem. The patient stated that only the use of TENS and pain medication permitted him to do the activities. He also complained of pain with forceful grasping. In the eighth and ninth weeks his grip strength actually declined. In the progress report written at the start of the ninth week of treatment, AROM measurements were virtually identical to those taken a month earlier, and left-hand grip strength had declined from a high of 37 pounds to 24 pounds, although hand closure had improved. Since AROM had remained stable and grip strength retrogressed in the previous month, a suggestion to discontinue therapy was unavoidable. At that time the patient had regained $55 \%$ of normal wrist extension/flexion, $25 \%$ of normal radial/ulnar deviation, and $75 \%$ of normal forearm rotation. Grip strength in the left hand was $35 \%$ of that in the dominant right hand. Functionally the right dominant hand remained impaired by pain and weakness and it appeared unlikely that the patient would be able to resume manual labor in the near future. Apparently the physician had nothing further to offer in the way of medical treatment and the patient was discharged. 
Patient D

This 62-year-old male fractured his left distal radius when he fell down some steps at his home. He was first referred for occupational hand therapy a week after the installation of an external fixator. An infection developed and persisted until the fixator was removed after eight weeks. Continued edema and inflammation in the left arm impeded therapy for the first month, and gains in AROM and strength were slow in coming. The patient was eventually diagnosed as having reflex sympathetic dystrophy. The physician instituted a series of stellate ganglion blocks, during which time therapy was continued. After $31 / 2$ months, the patient's modest gains had plateaued and therapy was discontinued. Seven months later, after surgery had been performed to remove significant scar mass and boney blocks, he was again referred for therapy. An external fixator, which had immobilized the patient's left wrist for several weeks, had just been removed. There was a severe loss of AROM at the wrist, and the patient was unable to actively rotate the forearm to a neutral position. Therapy was directed at increasing AROM of the wrist and forearm, with a precaution against strengthening activities for at least a month. The patient was invited to join the study, and he consented. Two activities were recommended for home program use, Numbers 4 and 5. At the end of the first week, the patient's left arm was red and tender to touch at the surgical scar. He reported overcomplying with home program activities and was cautioned to reduce his activity use to the recommended level. In the second week the 
erythema was gone and the patient stated that his arm was feeling fine. Activities 3 and 7 were added to his home program. The patient was instructed to monitor the condition of his arm carefully and cut back on repetitions if his pain levels increased or the redness reappeared. He continued to comply $100 \%$ as AROM and grip strength increased. With improved hand closure, the patient began using a hand exerciser in the fourth week. Activity 2 replaced Activity 4 in the fifth week. A progress report written near the end of the fifth week indicated that there had been good gains in wrist mobility and forearm rotation. The physician indicated that the fracture was not as well consolidated as he would have liked and cautioned against activities involving lifting. The patient had recorded high pain levels (7-8/10) with activity use from the start. This had varied a little from week to week but had not declined. At the end of the fifth week he reported an increase in pain and stiffness when inactive. In the middle of the seventh week the patient reported a further increase in pain and suggested that his arm was sore because he had slept on it. Edema in the forearm was slightly increased, but no heat or erythema had appeared. He was urged to contact his physician if the redness returned or the pain did not diminish quickly. When called, the physician told the patient to come and see him. He diagnosed an infection and prescribed antibiotic treatment. Therapy was put on hold for a week. In the ninth week, therapy and the home activity program were resumed. The patient was still taking antibiotics and reported 
his arm was feeling much better. Pain levels during activity use remained high in the ninth week but declined in the tenth and eleventh weeks. In the tenth week Activities 3 and 5 were discontinued and Activity 1 was added to the program. In the twelfth week therapy was again interrupted when the patient underwent surgery to remove internal fixation wires from his forearm. The patient returned to continue therapy two weeks later, just as the study was ending. He reported that his pain had decreased and there was no more sign of infection. At the time the study ended, the patient's wrist extension/flexion had increased to $73 \%$ of normal, wrist radial/ulnar deviation to $45 \%$ of normal, and forearm rotation to $56 \%$ of normal. Supination, which had been -15 at the beginning of treatment, had increased to $0 / 50$ degrees. Grip strength had increased from zero to $31 \%$ of that in the dominant right hand. The patient reported he was finally able to turn a doorknob with the left hand.

Patient $E$

This 54-year-old female sustained a crush injury to her left heel in an auto accident. Later the same day, while walking in her home with crutches, she fell and fractured the distal radius of her right arm. She is right hand dominant. The arm was initially immobilized in a cast but later found to require external fixation to stabilize the fracture. She was referred for therapy soon after the fixator was installed. At that time she appeared to be in great discomfort and very protective of the right arm. A severe loss of AROM was noted 
at the hand, elbow, and shoulder. After two weeks, therapy was terminated by her physician when she complained of excessive pain. Eight weeks later she was again referred to the Center for therapy, at which time she expressed frustration and perplexity at her failure to regain mobility. The external fixator had been removed. The right forearm and wrist were extremely immobile and hand closure was only fair. Her right hand grip strength measured 12 pounds. She complained of pain in the right shoulder. AROM of all the right upper extremity joints was impaired. She was still unable to walk unaided and was using a pickup walker fitted with a forearm trough. The patient blamed the use of this device for her shoulder pain. She was having great difficulty coping with the activities of daily living (ADLs) and appeared to be extremely tense and anxious. She was started on a regimen of hot packs, active and passive ranging, and graded activities and was instructed in relaxation techniques. Ten days after starting therapy, she was invited to join the study and consented to participate. Activities 2, 4 , and 6 were recommended for her home program, and she had difficulty complying only with Number 6 , the finger-in-ear. Gradually over the next four weeks her mobility and strength increased and so did her compliance, although her reported pain levels remained about the same. By the end of the third week she was able to ambulate with the aid of a cane. Because shoulder pain continued to make it difficult for the patient to move her right arm through space, it was suggested that she make use of Butchie's 
Pool, an indoor pool managed by the Easter Seals Association, where, supported by the water, she could stand and move about more freely. She found this to be very helpful. By the beginning of the fourth week, although continuing to use the walker, her shoulder pain had decreased sufficiently to permit the use of Activity 7. It replaced Activity 1. Activity 4 was made a little more difficult. Activity 6 was replaced by Activity 5 in the fifth week. AROM and grip strength continued to improve. During the fifth week, the patient reported that she had been able to "put up" her hair for the first time since the accident. In the sixth week she reported overcompliance with Activity 7. By the seventh and eighth weeks her compliance with home program activities was $100 \%$; she was independent in ADLs; and she had resumed a former hobby, with some difficulty, cutting out cloth patterns to make stuffed animals. Although she continued to use the home activity program as recommended, records of use for the ninth and tenth weeks are not available as the patient was not supplied with adequate score sheets. She resumed recording her activity use in the tenth week. Activity 3 was dropped. Activities 2 and 6 were revived and a new activity, Number 4, was added to the program. Compliance increased to $100 \%$ in the tenth and eleventh weeks.

By the eleventh week, the patient had regained $68 \%$ of normal wrist extension/flexion, 33\% of normal wrist radial/ulnar deviation, and $72 \%$ of normal forearm rotation. Her elbow extension had increased 40 degrees to -10 , shoulder flexion had increased 5 
degrees, and shoulder abduction had increased 40 degrees. Her right dominant hand grip strength had increased to 52\% of the left hand strength. At the time the study ended, this patient was continuing in therapy two days a week.

\section{Patient $F$}

This 68-year-old female fractured her right distal radius in a fall. She is right-hand dominant. The right arm was immobilized in a cast for six weeks, and the patient wore a rigid wrist support for another two weeks before she was seen for therapy. The right wrist and hand were edematous. This patient's AROM measurements at the start of therapy were nearly at functional limits, but her mildly limited range of motion, pain on movement, and loss of grip strength conspired to make the activities of daily living difficult. Her principal complaints were of inability to turn the ignition key of her car, open a door, or pick up an empty plate. She also had difficulty writing, a skill she relied on heavily in her job as a school testing specialist.

The patient was instructed in edema control measures and was started on a graded activity program. At the end of the first therapy session she was invited to join the study, and she consented. Three activities were recommended for this patient's initial home program, Numbers 2, 4 and 7. Activity 5 was added in the second week of treatment. Her reported pain levels declined the first two weeks. The rate of compliance decreased when a fifth activity, Number 3, was added in the fourth week but rebounded to 
$90 \%$ to $100 \%$ when Number 5 was discontinued. Throughout the course of therapy, the patient gained steadily in strength and mobility and reported decreased pain on movement. When her final progress report was written, the patient had regained $91 \%$ of normal wrist extension/flexion (up from 72\%), $77 \%$ of normal radial/ulnar deviation (up from 54\%), and $94 \%$ of forearm rotation (up from 85\%). Her grip strength had increased 16 pounds, to $73 \%$ of the strength of her nondominant left hand. She was back to her normal work and coping well with ADLs, although she reported that her arm was sore by the end of the day.

\section{Patient G}

This 34-year-old, right-hand dominant female fractured her right distal radius while playing vollyball. She worked as a medical transcriptionist who normally typed eight hours a day and, in addition, sometimes did typing at home in the evening. When she was first seen, the external fixator she had worn for approximately eight weeks had been removed and the resulting wounds were healed. She had not yet returned to work but reported that she could type up to 30 minutes before pain forced her to stop. She complained that she was unable to zip her jeans, turn her ignition key, or hold a plate or cup in the right hand, even when it was empty. The patient's forearm rotation into supination was poor, and the radial deviation was zero. The right wrist was edematous. Her gross grasp was good, and she had 13 pounds of right-hand grip strength. Pinch strength was also severely impaired. The patient 
was instructed in edema control measures and an activity program was initiated. When asked to join the study group, she consented. Activities 2, 4, 7, and 8 were included in her home program. since after the first few days she indicated good compliance with relatively little pain (in the range of 3 to 4 out of 10), Activity 6 was added. The recommended frequency of activity use was adjusted upward, and she continued to comply through the fourth week. Her reported pain during activity use was in the range of $2 / 10$ to $3 / 10$. As her mobility increased, the activities were modified to be more difficult. AROM and hand strength continued to increase as her activity use increased beyond the recommended frequencies. She also continued to do some typing work at home for an hour or two at a time. Near the end of the fourth week of treatment, she returned to work. By midweek she reported the pain in her arm had risen to $8 / 10$, and she stated she was unable to continue working and was taking pain medication in order to sleep. The pain quickly diminished as soon as she stopped working, and she was able to resume using the home program activities at a reduced frequency, as recommended.

The study ended when this patient was in the seventh week of treatment. At that time her wrist flexion/extension had returned to $67 \%$ of normal, radial/ulnar deviation was $54 \%$ of normal, and forearm rotation was $82 \%$ of normal. Radial deviation of the right wrist remained quite impaired at $0 / 5$ degrees, but supination was a functional $0 / 60$ degrees. The grip strength of her right dominant 
hand had increased to $54 \%$ of the left, and her ability to pinch had also improved. The patient reported she was coping well with her activities of daily living except for the typing by which she earned her living. She was planning to return to work the week after the study ended. At last report, she was working and the arm pain had increased but not quite to the level it reached after the first return to work. The order for therapy was discontinued by her physician in the eighth week of treatment.

\section{$\underline{\text { Patient } \mathrm{H}}$}

This 34-year-old male bus driver fractured his right distal radius when he fell off a roof he was trying to repair. When first seen, he had an external fixator in place. Three days after the fixator had been removed he was invited to join the study group, and he agreed. He had been receiving occupational hand therapy throughout the period of immobilization and began his participation in the study with good hand closure and a grip strength of six pounds. Four of the eight activities, Numbers 1, 2, 3, and 7, were recommended for this patient, and he reported perfect compliance with all of them. He also reported the least amount of pain of any of the participants in the study and gained steadily in strength and mobility. He returned to work, at light duty, after two weeks of therapy. In this instance, light duty meant that he was only required to drive the bus. As part of his full duties he was also required to push persons using heavy electric wheelchairs on and off the bus lifts. To help prepare him to resume full duties, in 
the second two weeks of therapy upper body strengthening was emphasized more than mobility. In the last two weeks he used only Activities 1 and 2. At the time his therapy was discontinued the patient had regained $85 \%$ of normal wrist flexion/extension, $77 \%$ of normal radial/ulnar deviation, and $100 \%$ of normal forearm rotation. His grip strength in the dominant right hand was $83 \%$ of that in the left. He resumed his full job responsibilities on the following Monday.

\section{Activity Use Data}

Each patient's home program included from two to six of the eight activities at any one time. In the total home program, each patient used from four to seven of the eight activities. Because the recommended frequency of use varied from patient to patient, and for the same patient over time, in order to make meaningful comparisons, the number of activity repetitions reported was converted to percentages of compliance. The measure of compliance was based on a comparison of the therapist's instructions with the frequency of use of home program activities self-recorded by each patient at the time the activity was performed. For instance, if the recommended frequency of use for Activity 1 was ten times, three times a day $(10 \times / \times 3)$, and the patient wrote $10 / 10 / 10$ in the boxes designated for Day 1, then the patient's percentage of compliance for that day was 100\%; therefore, the frequency of activity use was indicative of the level of compliance. 
In addition to recording their use of home program activities, the patients were also requested to note on the score sheet for each activity, twice a day, an estimate of the discomfort (or pain) they experienced while engaging in that activity. The estimates were to be expressed as a number between 1 and 10, with 1 representing no discomfort and 10 representing extreme pain. Using the 1 to 10 scale to estimate discomfort during activity use, and recording that number, proved to be more difficult for some patients than for others. Most of the patients recorded their pain estimates twice a day, as requested, most of the time. Some occasionally omitted one or both numbers on a particular day. One patient recorded his pain estimate every time he performed a set of repetitions and another recorded pain only once a day. Some patients occasionally wrote explanatory notes on their activity recording forms instead of using discomfort scale numbers. One patient was never able to arrive at a numerical estimate, although during therapy he described the extent of his discomfort when using the home program activities. His pain levels are indicated in the case study but no numbers were available to chart on the activity use graph. Despite these problems, it is believed that the pain levels reported while performing activities, when aligned with the bar graphs of activity use, shed some light on the influence of pain on the patients' use of home program activities.

A series of bar graphs was prepared to provide an overview of home activity program use by each patient throughout the course of 
therapy in relation to the discomfort experienced while performing the activities (Figure 1-8). In order to present the activity sequence in a reasonable amount of space, the reported number of times an activity was performed weekly was divided by the number of repetitions recommended per week to obtain a percentage of compliance with the activity for each week of therapy. A different crosshatch pattern was assigned to each of the eight activities, as shown in the legend accompanying the graphs. Beneath the vertical bar representing a patient's average weekly compliance with each prescribed activity, a number is located which represents the estimated discomfort level, on a scale of 1 to 10 , that the patient experienced during that activity. Thus Figures 1, 2, 3, 4, 5, 6, 7, and 8 illustrate the average weekly percentage of compliance with each of the activities recommended for use during each week of therapy in relation to the weekly average of discomfort/pain reported by Patients $A, B, C, D, E, F, G$, and $H$, while performing those activities.

The average percentage of patient compliance with all of the activities prescribed for their home programs, as reported by the eight patients in the study, is listed in Table 2. These percentages of compliance are reported in a bar graph in Figure 9.

The reported rates of compliance with each of the eight activities by all eight patients was averaged to determine whether 


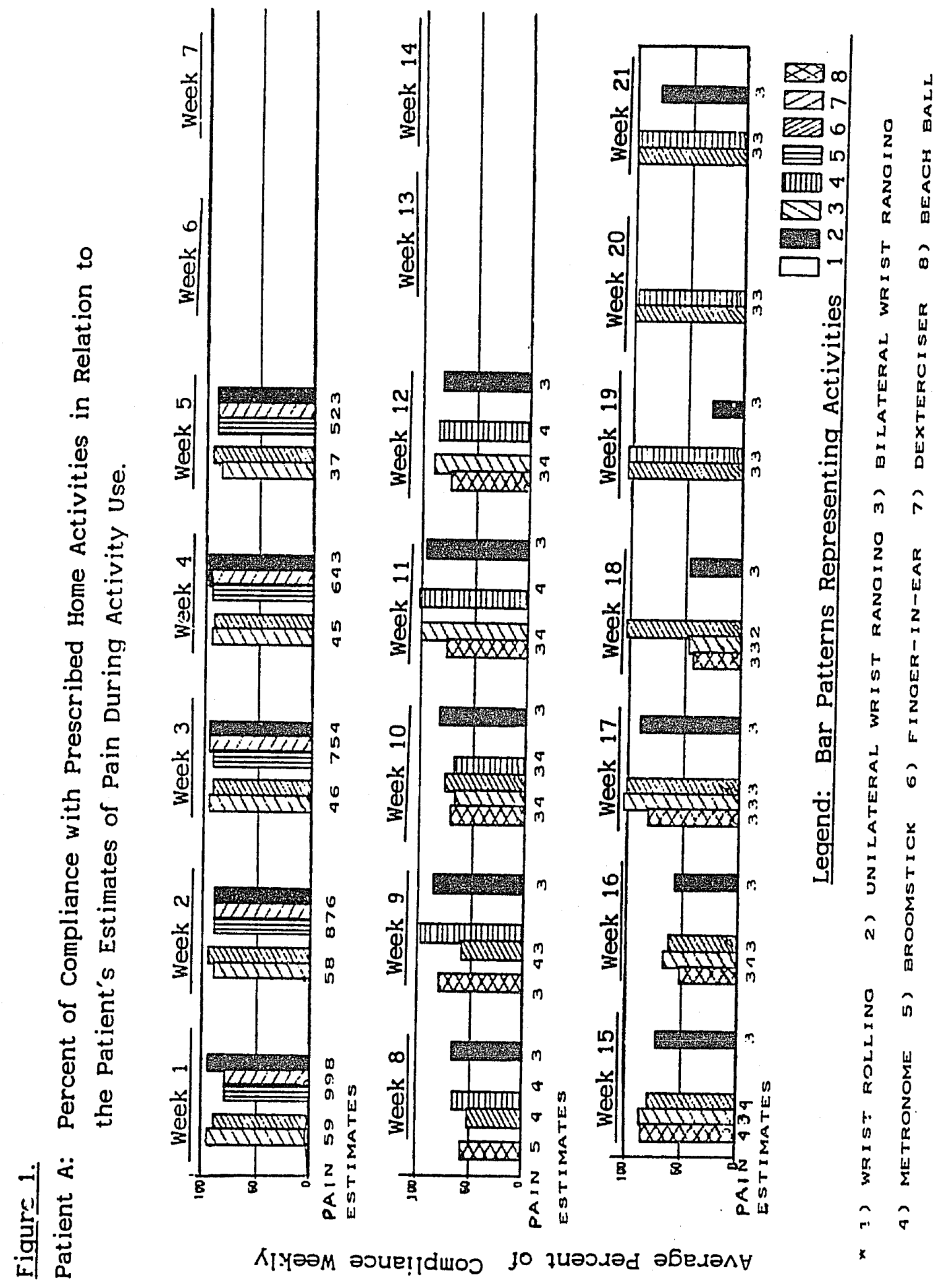




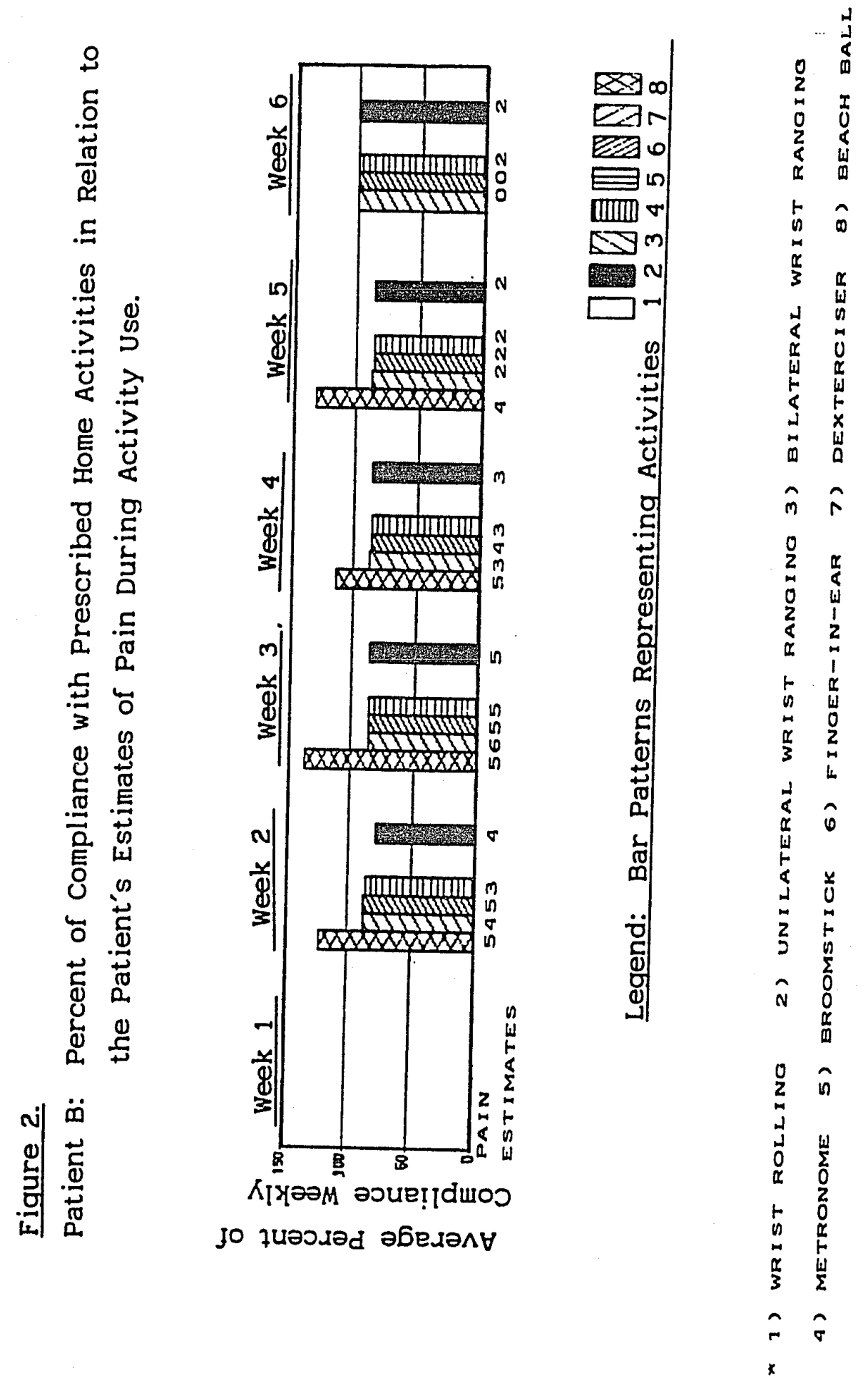




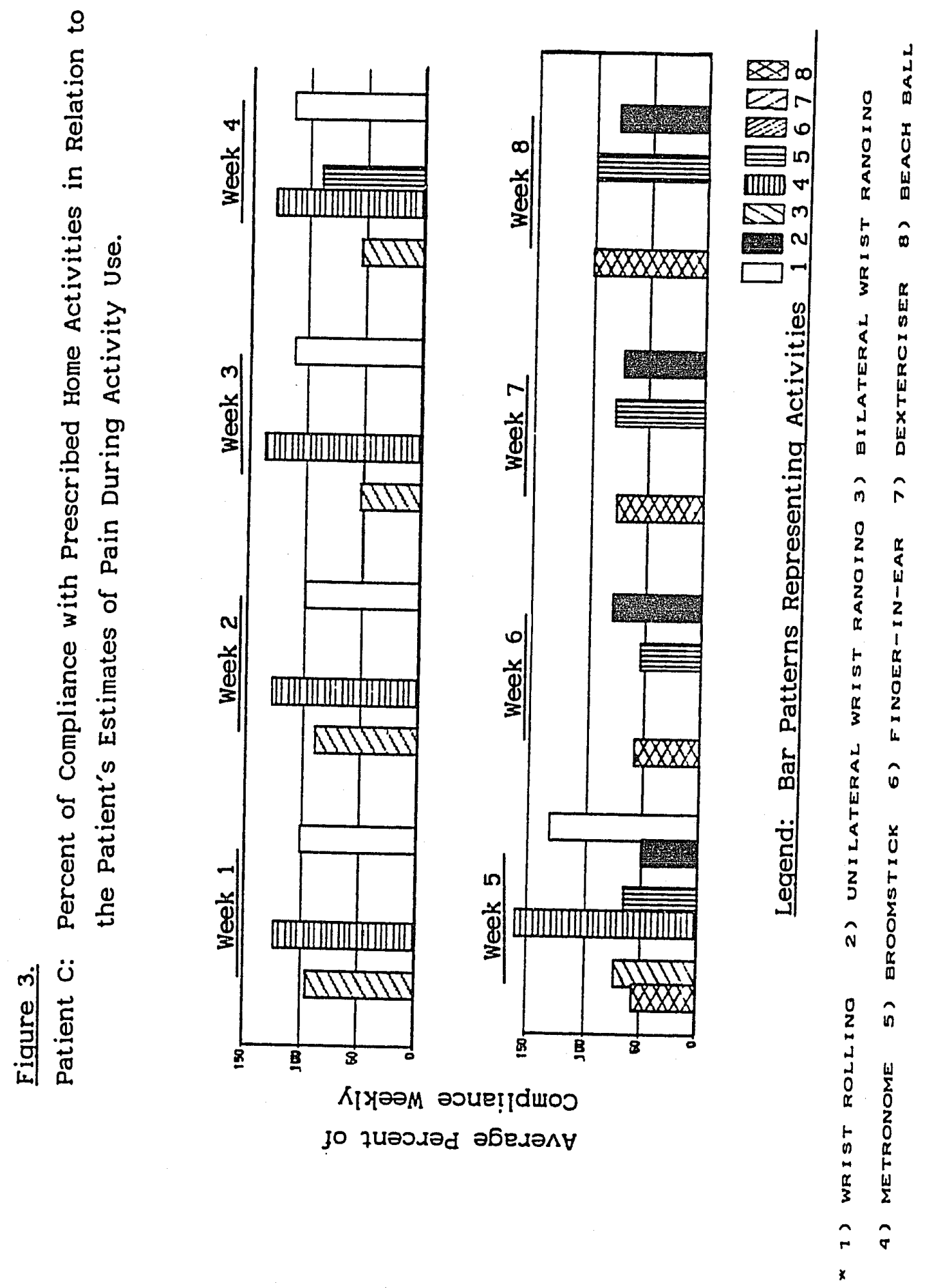




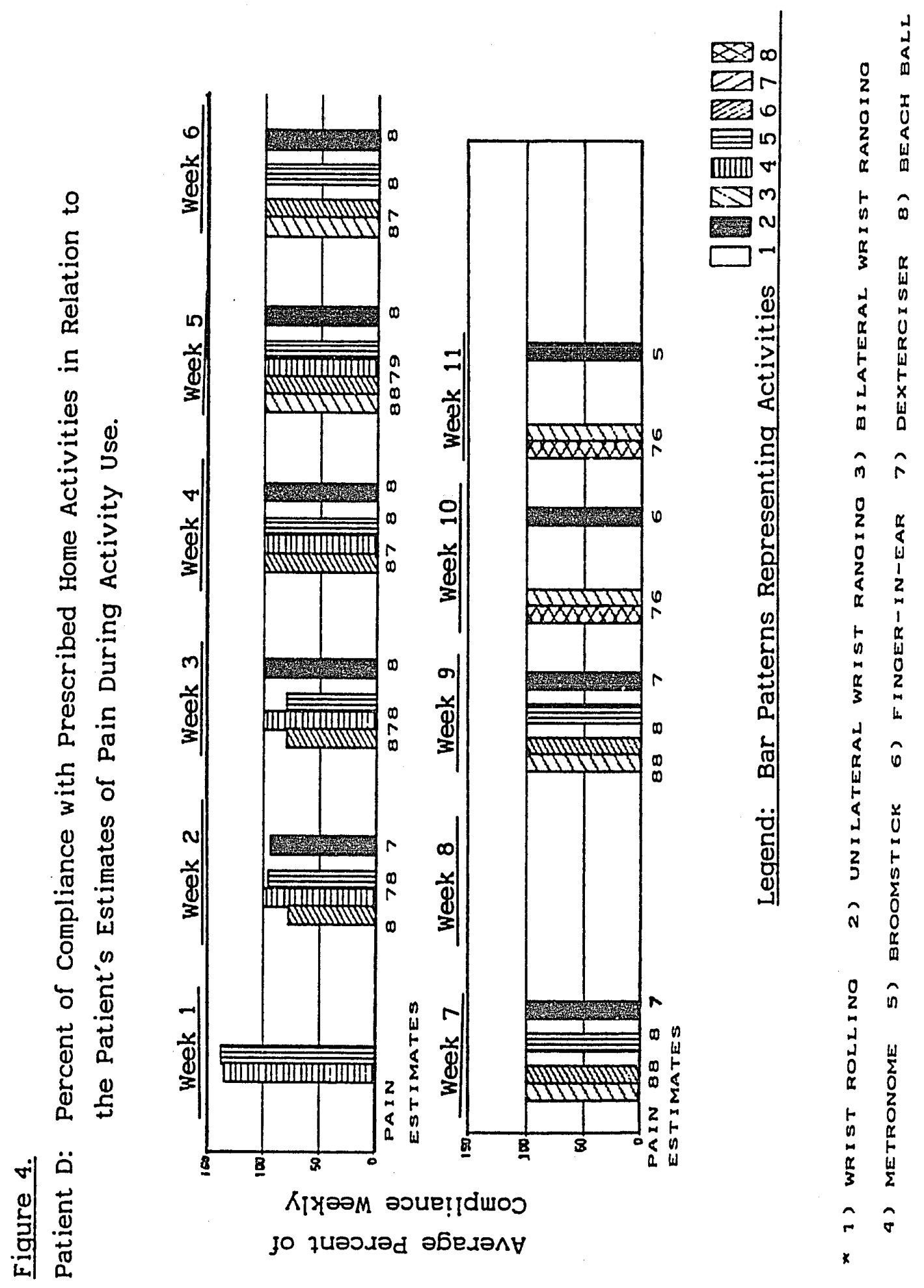




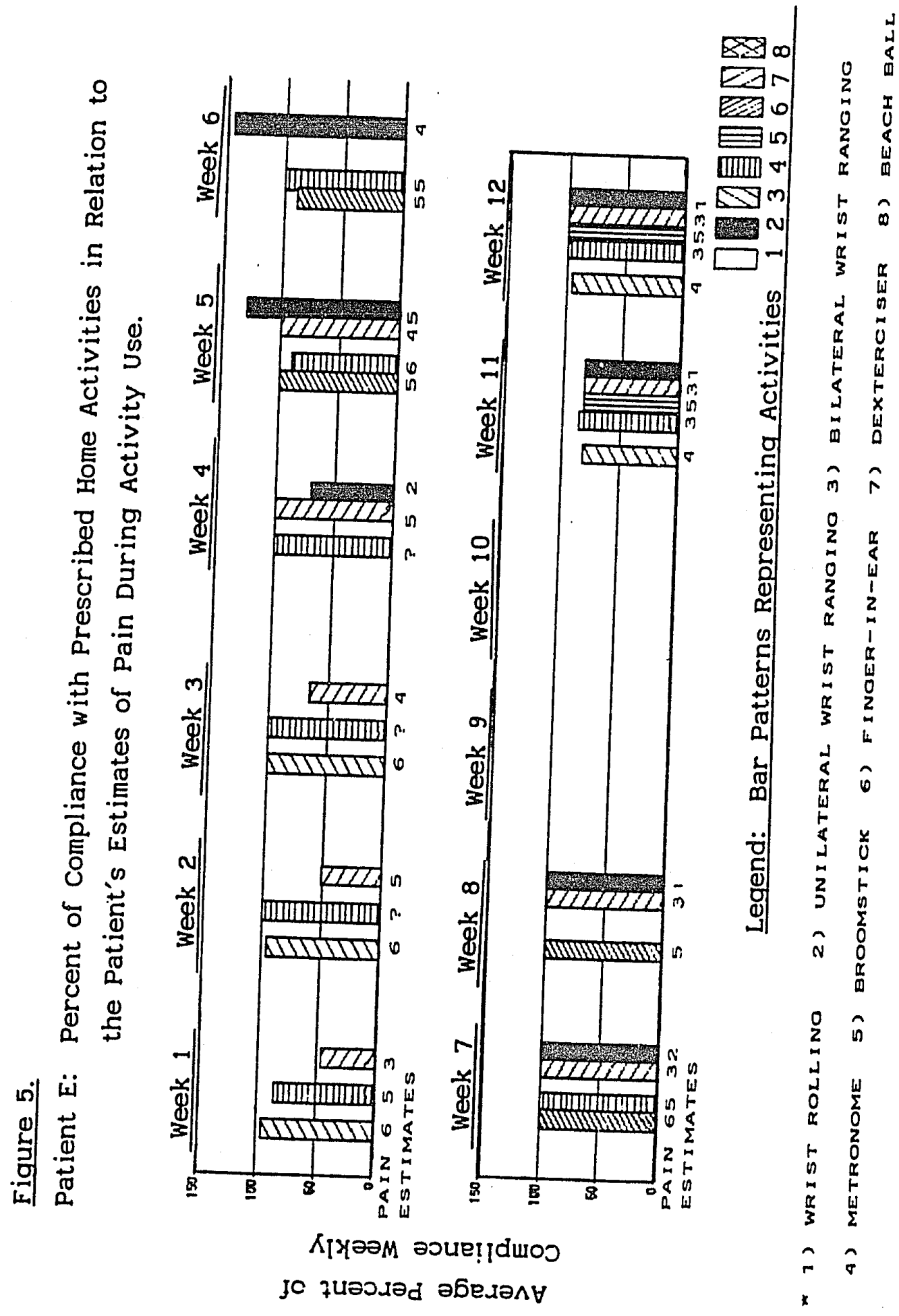




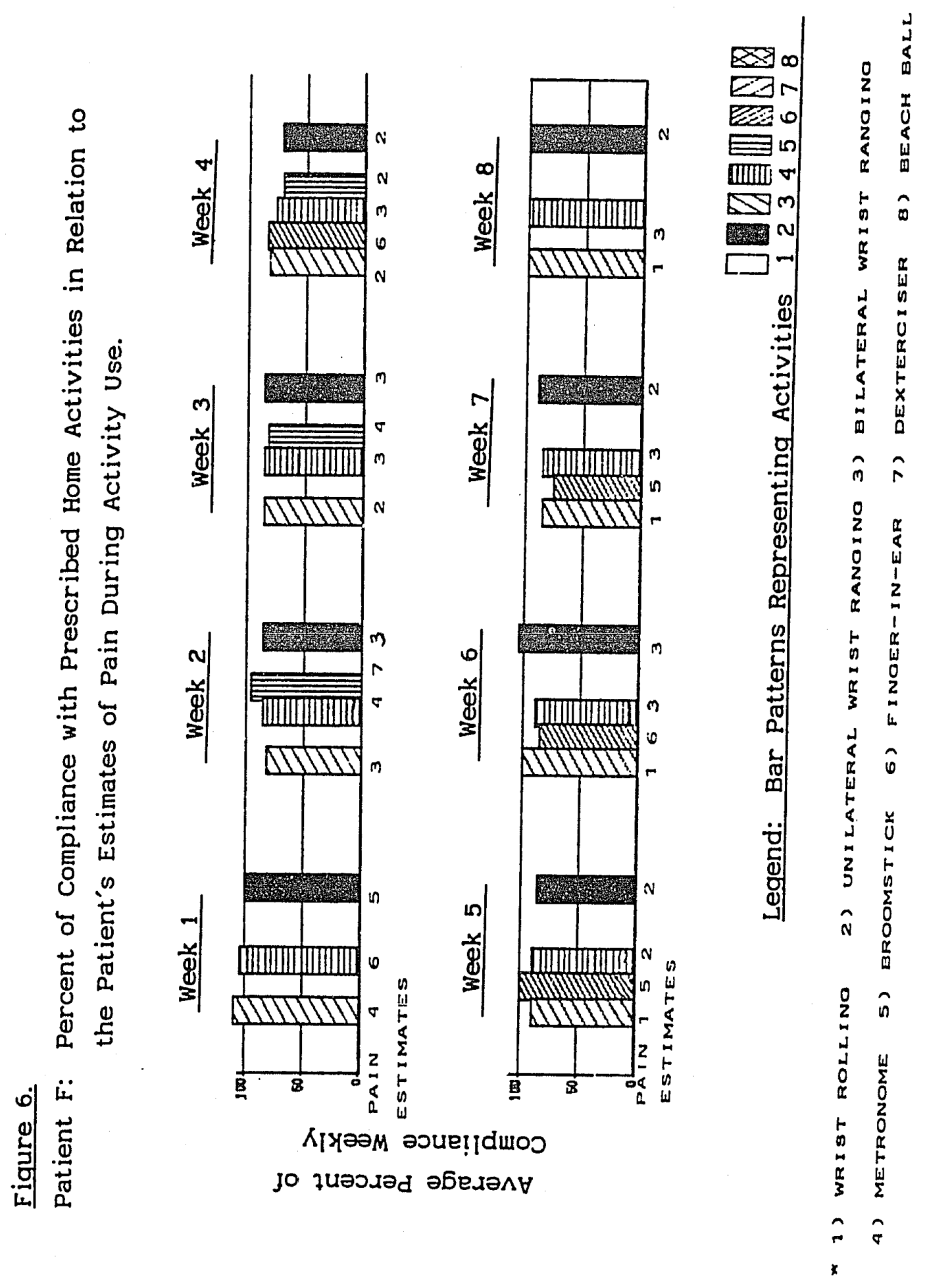




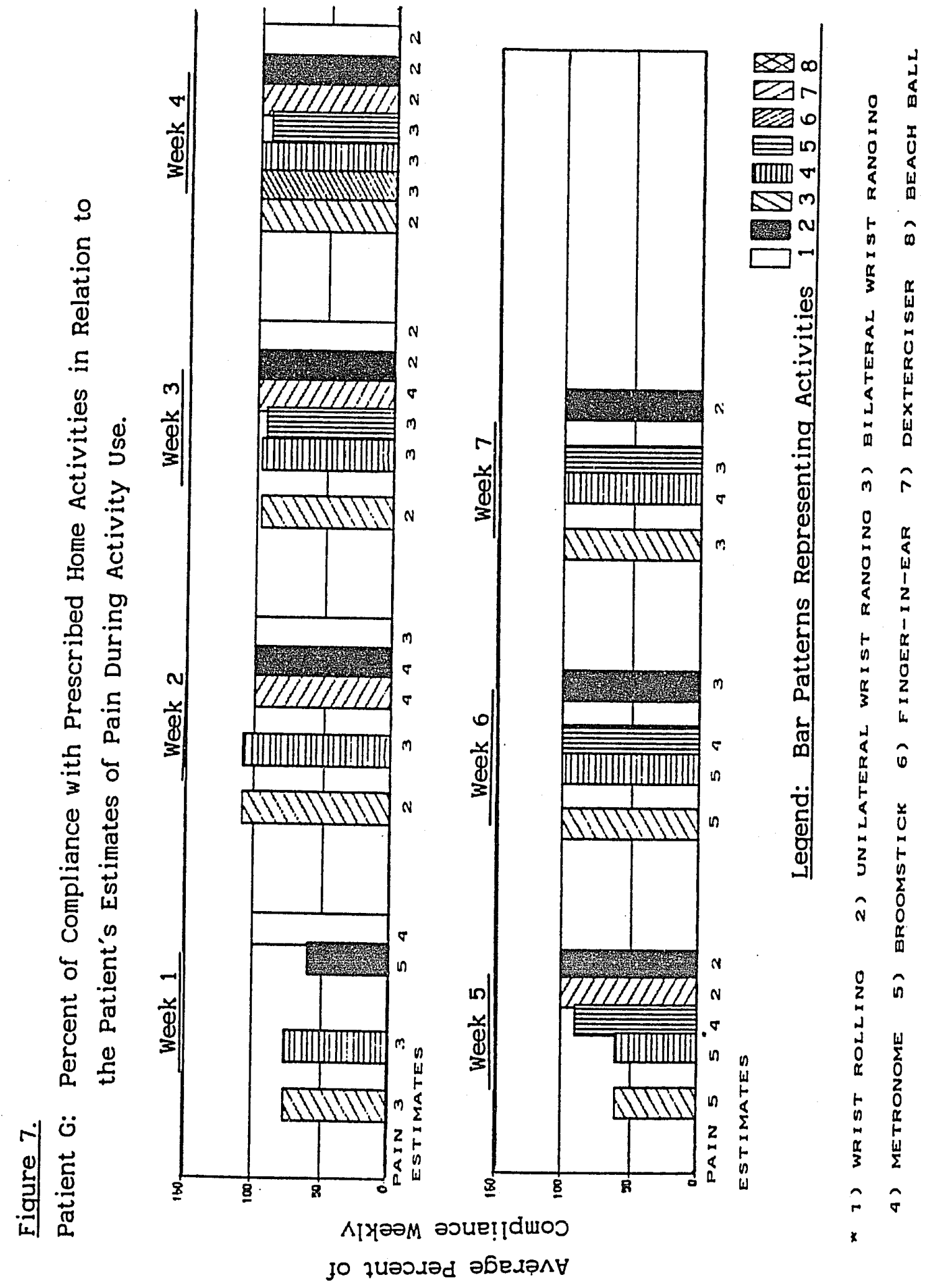




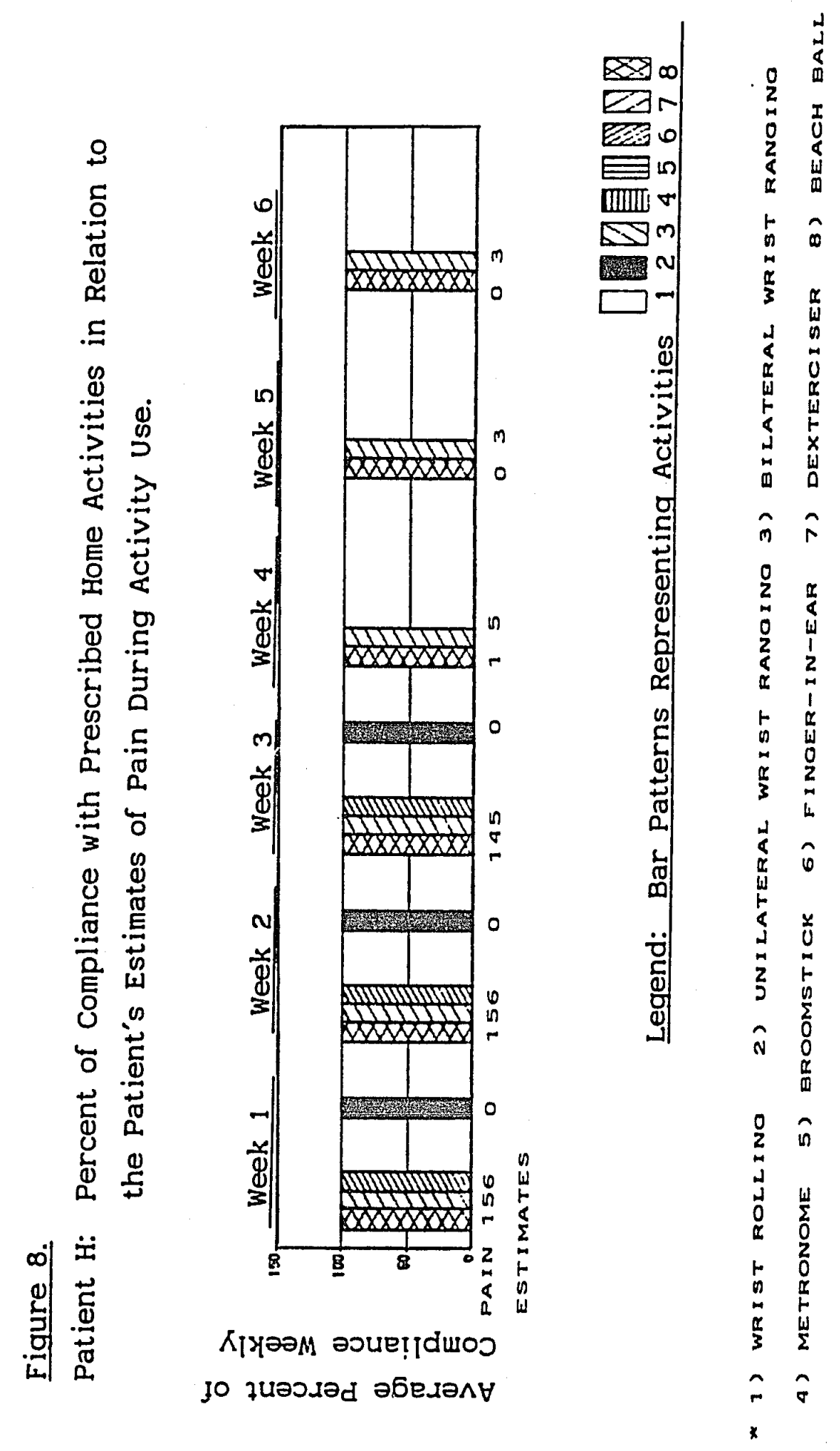


Table 2.

Average Percent of Compliance with the Activities Prescribed for Their Home Programs by All Patients $(N=8)$

\begin{tabular}{|c|c|c|c|c|c|c|c|c|}
\hline \multirow[t]{2}{*}{ Patient } & \multicolumn{2}{|c|}{ Percent } & \multicolumn{2}{|c|}{ f Compliance } & \multicolumn{2}{|c|}{ vith Activity } & \multicolumn{2}{|c|}{ Jumber* } \\
\hline & 1 & 2 & 3 & 4 & 5 & 6 & 7 & 8 \\
\hline$A$ & 69 & 85 & 86 & 90 & 89 & 90 & 81 & - \\
\hline B & 94 & 89 & 74 & 73 & - & - & 72 & - \\
\hline C & 79 & 73 & - & 136 & 78 & - & 71 & 111 \\
\hline D & 100 & 100 & 94 & 107 & 101 & - & 99 & - \\
\hline$E$ & - & 93 & 98 & 95 & 90 & 77 & 103 & - \\
\hline$F$ & - & 92 & 86 & 89 & 82 & - & 90 & - \\
\hline G & - & 92 & 100 & 92 & 95 & 100 & 94 & 100 \\
\hline$H$ & 100 & 100 & 100 & - & - & - & 100 & - \\
\hline
\end{tabular}

Note: A dash indicates that a subject did not use that activity.
* 1) Wrist Rolling
5) Broomstick
2) Unilateral Wrist Ranging
6) Finger-In-Ear
3) Bilateral Wrist Ranging
7) Dext erciser
4) Metronome
8) Beach Ball Rolling 


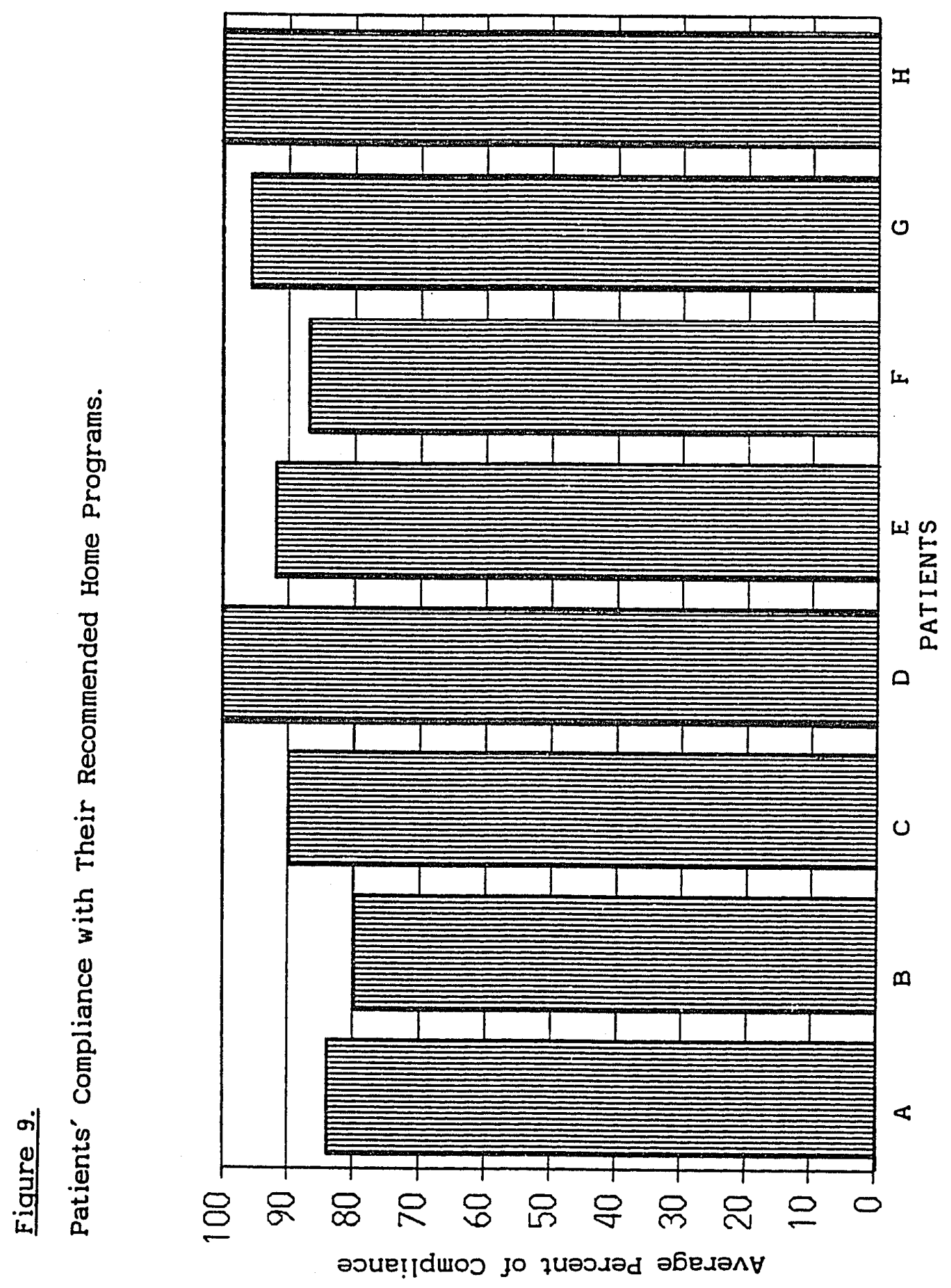




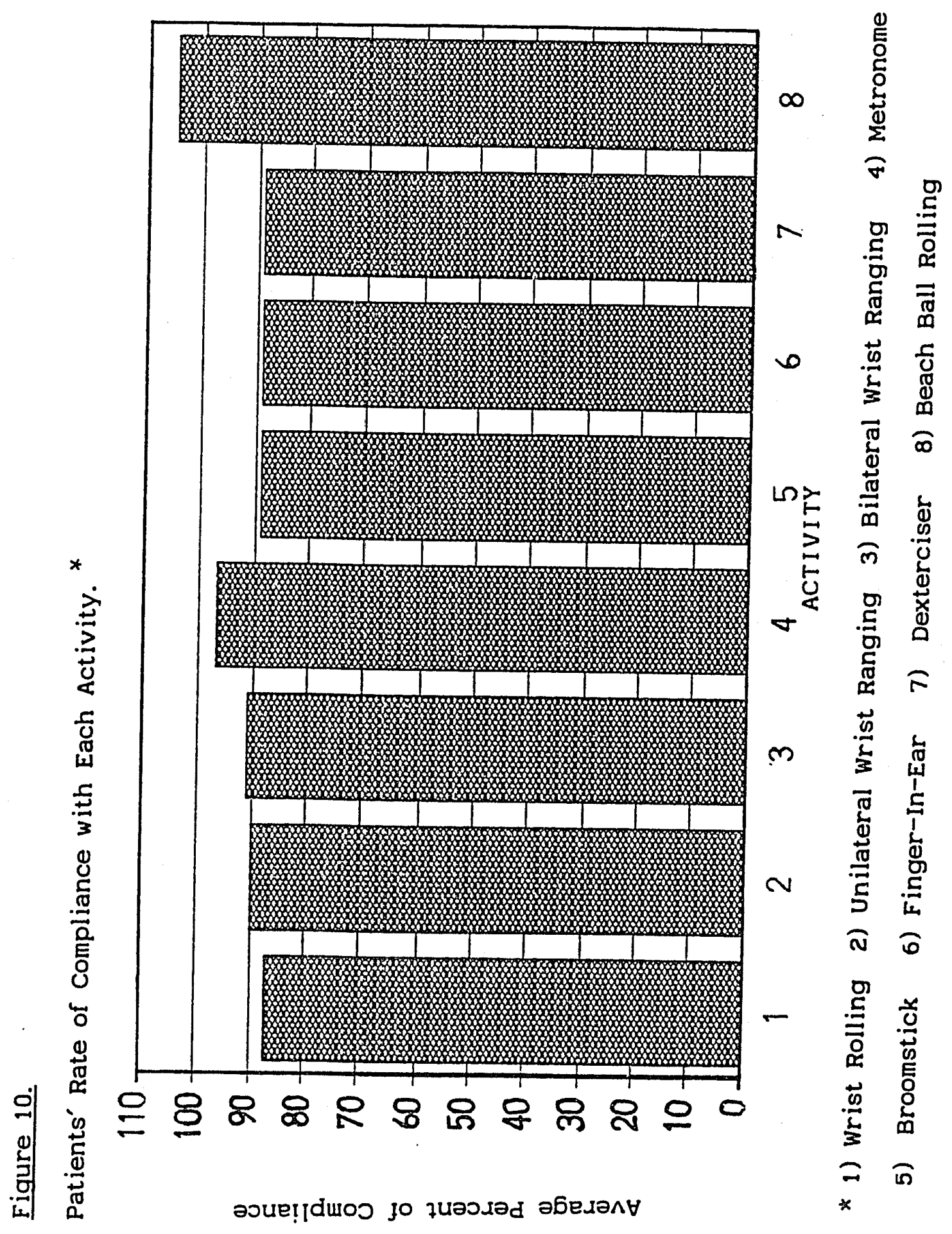


the eight activities varied in the degree of compliance accorded by the group of patients. The patients' average rate of compliance with each activity is illustrated in the bar graph in Figure 10.

\section{Grip Strength Data}

A measure of grip strength (gross grasp) in pounds was obtained bilaterally, using a Jamar dynamometer at the second setting, before and after treatment. Three trials were averaged on each occasion except when, although able to hold the dynamometer, the patient was unable to exert enough pressure with the injured hand to register a reading. The average grip strength of the injured hand was divided by the average grip strength of the uninjured hand to obtain a percentage of normal grip strength before and after treatment. The percentage of normal grip strength measurements before and after treatment for each patient are listed in Table 3.

\section{Active Range of Motion Data}

Each patient's active range of motion at the wrist and forearm of both upper extremities was measured in degrees at the beginning and end of treatment using standard instruments and techniques. In a few instances, when patient treatment was continued beyond the term of the study, the second measurement was made when the study ended. The before and after treatment measurements of wrist 
Table 3.

Grip Strength of the Injured Hand Before and After Treatment

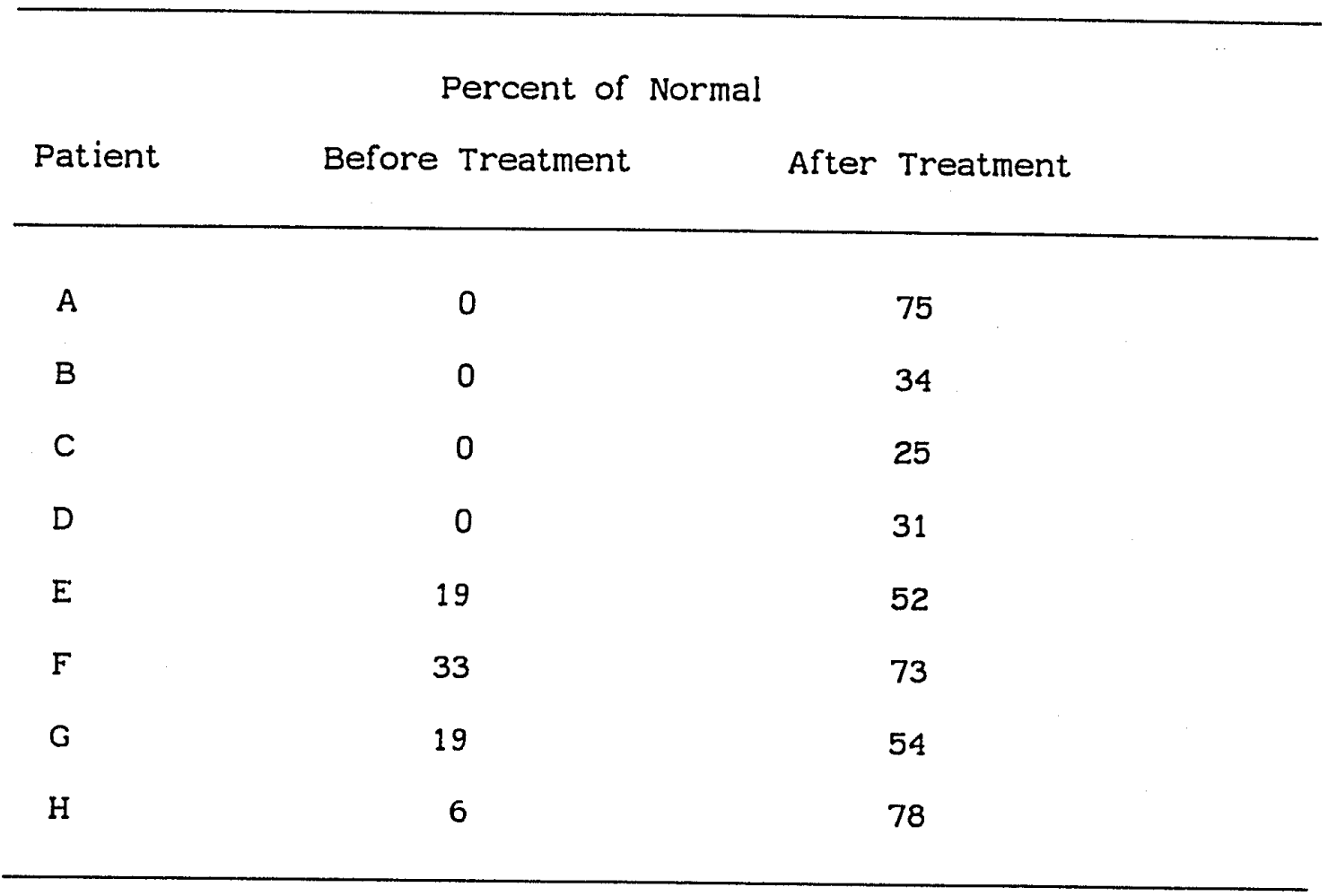


and forearm AROM of the eight patients are listed in Table 4. These are referred to in the table as Prior and Post treatment measurements.

Table 5 was prepared to illustrate the patients' gains in AROM in comparison with their average rates of compliance with home program activities.

Results

The first question posed for this study was, "What is the frequency of compliance with each of the activities in a home activity program reported by outpatients with upper extremity joint stiffness that followed immobilization from fractures, contusions or crush injuries?" The average rate of compliance with each of the eight activities by all subjects in the study was found to range from $87 \%$ to $105 \%$, with a mean of $92 \%$. The percentage of compliance by this group of subjects was highest for Activity 8 , beach ball rolling, and lowest for Activity 1, wrist rolling. The average rates of compliance by individual patients with each of the activities in their prescribed programs varied more widely, from $100 \%$ compliance with all prescribed activities by Patient A, to a range of $71 \%$ to $136 \%$ compliance with his prescribed activities by Patient C. A more detailed examination of home activity program compliance, as shown in the patients' activity use graphs, revealed that compliance with the prescribed activities by some patients varied greatly from week to week as life events and the condition 
Table 4

Active Range of Motion of the Patients' Wrist and Forearm Prior and Post Treatment, Expressed in Degrees $(\mathrm{N}=8)$

Patient Joint Motion Prior Post Joint Motion Prior Post

A Wrist Extension $0 / 25 \quad 0 / 65^{*}$ Flexion $0 / 15 \quad 0 / 55$

$\begin{array}{llllll}\text { Wrist } R D^{* *} & 0 / 0 & 0 / 15 & U D & 0 / 20 & 0 / 25\end{array}$

Forearm Supination 0/0 0/65 Pronation 0/55 0/70

B Wrist Extension $0 / 20 \quad 0 / 50 \quad$ Flexion $\quad 0 / 25 \quad 0 / 45$

$\begin{array}{llllll}\text { Wrist RD U D } & 0 / 10 & 0 / 15 & 0 / 20\end{array}$

Forearm Supination $0 / 30 \quad 0 / 60 \quad$ Pronation $0 / 85 \quad 0 / 85$

$\begin{array}{lllll}\text { C Wrist Extension } 0 / 45 \quad 0 / 50 \quad \text { Flexion } & 0 / 5 & 0 / 55\end{array}$

$\begin{array}{llllll}\text { Wrist RD } & 0 / 15 & 0 / 20 & \text { U D } & 0 / 5 & 0 / 25\end{array}$

Forearm Supination $0 / 50 \quad 0 / 60 \quad$ Pronation $0 / 60 \quad 0 / 75$

D Wrist Extension $\quad 0 / 20 \quad 0 / 55 \quad$ Flexion $0 / 15 \quad 0 / 60$

$\begin{array}{llllll}\text { Wrist R D } & 0 / 5 & 0 / 15 & \mathrm{U} D & 0 / 15 & 0 / 15\end{array}$

Forearm Supination $-15 \quad 0 / 50 \quad$ Pronation $-15 / 45 \quad 0 / 80$

E Wrist Extension $0 / 25 \quad 0 / 40 \quad$ Flexion $0 / 40 \quad 0 / 45$

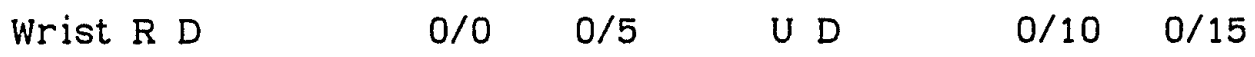

Forearm Supination $0 / 5 \quad 0 / 45 \quad$ Pronation $0 / 65 \quad 0 / 70$ 
Table 4, continued.

\begin{tabular}{|c|c|c|c|c|c|c|}
\hline \multirow[t]{2}{*}{$E$} & \multicolumn{2}{|c|}{ [Elbow Extension/Flexion } & \multirow{2}{*}{$\begin{array}{l}\text { Before } \\
0 / 150\end{array}$} & \multirow{2}{*}{$\begin{array}{l}-50 / 135 \\
\text { Abduction }\end{array}$} & \multirow{2}{*}{$\begin{array}{l}\text { After } \\
0 / 90\end{array}$} & \multirow{2}{*}{$\begin{array}{c}-10 / 155] \\
0 / 130\end{array}$} \\
\hline & Shoulder Flexion & $0 / 90$ & & & & \\
\hline \multirow[t]{3}{*}{$F$} & Wrist Extension & $0 / 70$ & $0 / 80$ & Flexion & $0 / 45$ & $0 / 60$ \\
\hline & Wrist $R \quad D$ & $0 / 0$ & $0 / 15$ & $U D$ & $0 / 20$ & $0 / 25$ \\
\hline & Forearm Supination & $0 / 60$ & $0 / 75$ & Pronation & $0 / 80$ & $0 / 80$ \\
\hline \multirow[t]{3}{*}{$G$} & Wrist Extension & $0 / 45$ & $0 / 55$ & Flexion & $0 / 20$ & $0 / 45$ \\
\hline & Wrist $R D$ & $0 / 0$ & $0 / 5$ & U D & $0 / 25$ & $0 / 30$ \\
\hline & Forearm Supination & $0 / 25$ & $0 / 60$ & Pronation & $0 / 75$ & $0 / 75$ \\
\hline \multirow[t]{3}{*}{$\mathrm{H}$} & Wrist Extension & $0 / 50$ & $0 / 75$ & Flexion & $0 / 50$ & $0 / 90$ \\
\hline & Wrist $R \quad D$ & $0 / 5$ & $0 / 30$ & $U D$ & $0 / 30$ & $0 / 35$ \\
\hline & Forearm Supination & $0 / 75$ & $0 / 90$ & Pronation & $0 / 80$ & $0 / 85$ \\
\hline
\end{tabular}

* The first number represents neutral range; the second number represents the degree of mobility. ** $R D$ is an abbreviation for radial deviation. $U D$ is an abbreviation for ulnar deviation. These terms describe lateral movements of the wrist joint. 
Table 5.

Patients' Joint Mobility Gains, Expressed in Degrees, Compared With Their Average Rates of Home Activity Program Compliance

Joint Mobility Patient

in Degrees $A$ A $B$ C $D$ D $F \quad G \quad H$

\begin{tabular}{lrrrrrrrr} 
Wrist Extension & 40 & 30 & 5 & 35 & 25 & 10 & 10 & 25 \\
Wrist Flexion & 40 & 20 & 50 & 45 & 5 & 15 & 25 & 40 \\
Radial Deviation & 15 & 5 & 5 & 10 & 5 & 0 & 5 & 25 \\
Ulnar Deviation & 5 & 5 & 20 & 0 & 5 & 15 & 10 & 5 \\
Forearm Supination & 65 & 30 & 10 & 65 & 40 & 15 & 35 & 15 \\
Forearm Pronation & 15 & 0 & 15 & 35 & 5 & 0 & 0 & 5 \\
\hline
\end{tabular}

Total Degrees of

Motion Gained in $180 \quad 90 \quad 105 \quad 190 \quad 145 \quad 55 \quad 85 \quad 115$

Wrist and Forearm

Average Percent

$\begin{array}{lllllllll}\text { of Compliance } & 84 & 80 & 90 & 100 & 92 & 87 & 96 & 100\end{array}$ 
of their injured extremities influenced their ability to comply.

The second question generated for this study was, "What is the relationship between gains in active range of motion and the frequency of compliance with one or more recommended home program activities as reported by outpatients with upper extremity joint stiffness that followed immobilization for fractures, contusions, or crush injuries?"

As expected, all eight patients gained AROM in their impaired upper extremity joints. With respect to some joint motions, full normal AROM was achieved by some of the patients (Patients $B, F$ \& H). Concurrently with AROM increases, the patients gained grip strength and recovered functional use of their injured limbs, of ten to the extent to become independent in ADL and successfully resuming their former employment. As shown in Table 5, only Patients $D$ and $H$ rendered $100 \%$ (average) compliance with the recommended home program activities and they achieved, respectively, a total of 190 and 115 degrees of motion, whereas Patient A, who gained 180 degrees of total motion gave an average compliance of only $84 \%$ and Patient $F$, who gained the least AROM (55 degrees total) averaged $87 \%$ compliance. The average levels of compliance reported by this sample of patients was so high overall that any association between poor compliance and lower gains in AROM was not found. Although it can be seen that home program activity use contributed in some measure to the rehabilitation of these patients, the relationship between compliance and gains in AROM is inconclusive. 


\section{CHAPTER 5}

\section{DISCUSSION, IMPLICATIONS AND RECOMMENDATIONS}

This multiple case study of eight patients with hand injuries documented their progress throughout four to twenty-one weeks of hand rehabilitation. As a part of their occupational therapy, the patients were provided with activity programs to be performed independently at home and asked to self-record their use of these activities. They were also requested to record estimates of their discomfort or pain while engaged in the activities. These self-records were used to determine how well the patients complied with their home activity programs. The active range of motion of the upper extremity joints of the patients was measured when they joined the study and again when it ended, or when their therapy was concluded.

The eight patients who participated in the study appeared to have been exceptionally well motivated to succeed in their rehabilitation. While only one of the eight complied with his activity program absolutely, the reported rates of activity use by the entire group were extremely high. In their study of patient compliance with home exercise programs, Codori, Nannis and Pack stated that noncompliance was pervasive and that patients rarely reported their failure to comply. This phenomenon has been observed by this investigator as well and was, in fact, the impetus for embarking on the study. The patients in this study, however, 
reported their lapses candidly and their incidents of noncompliance were brief and temporary. In these generally compliant patients, over use of the prescribed activities was more problematical than under use. The reasons for that surprising development invite examination.

Perhaps the most obvious explanation is that the recording process itself induced more diligent performance (Nelson, 1977). It is also possible that the "Hawthorne Effect" inspired the patients to out-perform some unknown others with whom they might be compared unfavorably (Issac \& Michael, 1981). They may have simply been eager to please their therapists (Codori, et al; 1992) and one cannot discount the possibility that they may have provided false reports. All of these factors may have contributed to the high rates of activity use, although the last one, fabrication, was probably not operative to any significant degree, for the following reasons. These patients were observed to strive for greater achievement during their therapy sessions and demonstrated proficiency in the prescribed activities. Except for the times when physical setbacks or stressful life situations intervened, all but one of the patients progressed steadily in the recovery of functional abilities. This would tend to indicate that they were "doing their homework".

To all appearances, these were goal oriented, serious people, who were determined to regain their lost skills and get back to the business of earning a living. These are admirable qualities in a 
person and in a patient. It was unfortunate, however, for the purposes of the study that all of the patients enrolled seemed to be so dedicated to recovery. A question as yet unanswered is, would patients known to be lax in their use of home program activities become more compliant if exposed to the same conditions as the patients in the study?

The response of some of the patients studied to pain is of some interest. Many, if not most, people presenting themselves for therapy express more or less anxiety about how much the treatment is going to hurt. An important aspect of early therapy is reassuring the patient that it is all right to move the injured limb (Morey \& Watson, 1986). These patients were no exception. Most of the study participants followed the expected course, beginning active movement tentatively and increasing activity use as discomfort subsided. A few, however, once they were convinced that moving the injured limb was safe and necessary, showed phenomenal zeal in carrying out their home program activities while reporting very high pain levels. It is believed that these individuals were operating under the influence of the "No pain, no gain" school of thought despite their therapist's admonishments to the contrary.

Despite all of the above, these patients were neither saints nor martyrs. As already stated, all but one did on occasion fail to comply. One curtailed his program on sundays, another was noncompliant during the Christmas holidays. One became noncompliant when he went hunting, and another "had no time for 
activities" while on a business trip. From a therapeutic viewpoint, home program activities should be engaged in daily (Mackin, 1986). Stiffness and scar development do not take a holiday. It may not, however, be realistic to suggest to generally compliant patients that nothing must be allowed to interfere with therapy. As long as the patient is progressing and does not report habitual noncompliance, offering some latitude in the use of activities may not only be unavoidable but may be desirable when treating responsible adults.

Even in this small group of patients, whose diagnoses were basically similar, the complexity of the injuries varied greatly from patient to patient. Injuries to other parts of the body (wrist, shoulder, and even a foot), infections, and irritation by internal fixation devices, conspired to invalidate generalizations about the efficacy of activity use. This points to the difficulty of conducting research with human subjects. Ideally, to test the effectiveness of activity use, every subject would have been required to use all of the activities being studied equally, and only those activities, under identical conditions and for the same length of time (Grey, 1986). In the context of treatment, home program recommendations were necessarily guided by each patient's progressive healing and their response to therapy. Program individualization renders useful comparisons difficult. Since the data did not indicate that any of the activities studied was superior in remediating stiffness following trauma and immobilization, discovering the "best activities" for each patient remains an empirical process. The case study data revealed 
some instances of inadequate communication between the patient and the therapist which resulted in the loss of data. It also pointed out the need to closely monitor patients' use of home activity programs in order to keep the program requirements adjusted to the patients' capabilities.

As an integral part of the patients' therapy, it is believed that every activity they used facilitated some phase of their recovery and contributed to whatever measure of recovery they achieved. In addition to home program use, however, the interaction of many factors influenced the patients' rehabilitation. to name but a few; the severity of the original injury, complicating injuries to other parts of the body, the extent of AROM loss, the duration of treatment, the presence of foreign bodies (internal fixators) and infections, subsequent minor traumas, return to work stress, and persistent pain.

\section{Implications for Practice}

The results of this study suggest that the the self-recording of home program activity use might be useful to enhance patients' compliance with their home activity programs. Such records might also improve the therapist's oversight of patients' activity use. Keeping a record of activity use is likely to increase the patients' awareness of what needs to be done to promote recovery. The 
presentation of the record to the therapist might also serve as stimulus to communication about any problems or concerns the patient is experiencing in connection with the activities.

\section{Recommendations and Questions for Further Study}

Further investigation into the role of self-record keeping in patient compliance could prove to be a worthwhile endeavor. It would be of interest to determine whether immediate self-recording of home program activity use would increase compliance by patients who have tended to undercomply. The data collected for this study was inconclusive with regard to the relationship between any specific activities and increased upper extremity AROM; therefore, it cannot be said with confidence that none exists. A larger and more rigorous investigation might yet provide answers leading to improvements in home activity program development.

This study provided only partial answers to the questions posed. It also generated more questions than it answered, such as: What makes patient A more compliant than patient B?, Does 100\% compliance suggest that the program is too easy?, Is perfect compliance a reasonable goal or should patients be given more latitude to adjust their programs or design their own home activity programs?, Is pain a deterrent to activity use, or does it drive some patients to try even harder?, How much pain should a patient be encouraged to endure? Are some activities more intrinsically 
motivating than others? Answers to questions like these would provide information which would be useful for application in occupational therapy practice. 


\section{REFERENCES}

American Occupational Therapy Association. (1974). A Curricum Guide for Occupational Therapy Educators, Rockville, Maryland: American Occupational Therapy Association.

Codori, A., Nannis, E. D., \& Pack, A. D. (1992). The development of a clinical measure of compliance with hand rehabilitation, Journal of Hand Therapy 5 (1) 29-33.

Bear-Lehman, J. (1983). Factors affecting return to work. The American Journal of Occupational Therapy 37, 189-194.

Bear-Lehman, J. \& Flinn-Wagner, S. (1988). Hand rehabilitation and occupational therapy: Implications for practice. In F. S. Cromwell, \& J. Bear-Lehman (eds.) Hand Rehabilitation in Occupational Therapy (p. 8). New York: The Haworth Press.

Caron, H. \& Roth, H. (1971). Objective assessment of cooperation with an ulcer diet: Relation to antacid intake and to assigned physician, American Journal of Medical Science, 261, 61-66.

Caroll, D. (1965). A quantitative test of upper extremity function. Journal of Chronic Diseases, 18, 479-496. 
Curtis, R. M. (1990). Management of the stiff hand. In H. M. Hunter, L. H. Schneider, E. J. Mackin, \& A. D. Callahan (eds.), Rehabilitation of the Hand (pp. 321-327). St. Louis: The C. V. Mosby Co.

Feinberg, J. \& Brandt, K., (1981). Use of resting splints by patients with rheumatoid arthritis, The American Journal of Occupational Therapy, 35, 173-178.

Frykman, G. K. \& Nelson, E. F. (1990). Fractures and traumatic conditions of the wrist. In H. M. Hunter, L. H. Schneider, E. J. Mackin, \& A. D. Callahan (eds.), Rehabilitation of the Hand (pp. 267-283). St. Louis: The C. V. Mosby Co.

Grey, M. (1986). Experimental and quasi-experimental designs. In G. Lo-Biondo-Wood \& J. Haber (eds.), Nursing Research: Critical Appraisal and Utilization (pp. 114-127). Saint Louis: C. V. Mosby Co.

Hardy, M., A. (1986). Preserving function in the inflamed and injured hand. In C. A. Moran, Hand Rehabilitation (p. 1). New York: Churchill Livingstone.

Issac, S. \& Michael, W. B., (1981). Handbook in Research and Evaluation (2nd ed.) (p. 85). San Diego: Edits Publishers. 
Jebsen F. H., Taylor, N., Trieschmann, R. B., Trotter, M. J., and Howard, L. A. (1969). An objective and standardized test of hand function, Archives of Physical Rehabilitation, 50, 311-319.

Klein, R. M. \& Bell, B. J., (1882). Self-care skills: Behavioral measurement with klein-bell adl scale. Archives of Physical Medicine, 63, 63-68.

Lynch, K. B. \& Bridle, M. J., (1989). Validity of the jebsen-taylor hand function test in predicting activities of daily living. The Occupational Therapy Journal of Research, 9 , 316-319.

Mackin, E. J. (1986). Prevention of complications in hand therapy. In R. A. Chase (ed.), Hand Clinics, 2 (2), 429-447.

MCEntee (1990). Therapist's management of the stiff hand. In H. M. Hunter, L. H. Schneider, E. J. Mackin, \& A. D. Callahan (eds.), Rehabilitation of the Hand (pp. 328-341). St. Louis: The C.V. Mosby Co.

McGee Johnson, J. I. (1988). A crush injury to the dorsum of the right wrist. Journal of Hand Therapy 1 (2), 91-93. 
Melvin, J. L., (1985). Roles and functions of occupational therapy in hand rehabilitation, The American Journal of Occupational Therapy, 39, 795-798.

Morey, K. R. \& Watson, A. H., (1986). Team approach to treatment of the posttraumatic stiff hand. Physical Therapy, February. $225-228$.

Mosey, A. C. (1981). Occupational Therapy: Configuration of a Profession (pp. 74-79). New York: Raven Press.

Murphy, R. (1987). The Body Silent (p. 50). New York: Henry Holt.

Nelson, R. O., (1977). Methodological issues in assessment via self-monitoring. In Cone, J. D., New Directions in Clinical Psychology (pp. 217-240). New York: Bruener-Mazel.

Pedretti, L. W. \& Pasquinelli (1990). A frame of reference for occupational therapy in physical dysfunction. In L. W. Pedretti, and B. Zoltan, Occupational Therapy Practice Skills for Physical Dysfunction, (3rd ed.) (pp. 1-5). St Louis: The c. V. Mosby Co. 
Representative Assembly of the American Occupational Therapy Association (1979). Resolution C: The philosophical base of occupational tirerapy. The American Journal of Occupational Therapy, 33, (12), 785.

Salter, M. I., (1987). Hand Injuries: A Therapeutic Approach (pp. 190-199). New York: Churchill Livingstone.

Smith, H. B., (1973). Smith hand function evaluation. The American Journal of Occupational Therapy, 27, 244-251.

Sorensen, M. K. (1986). Fractures of the wrist and hand. In C. A. Moran, Clinics in Physical Therapy (pp. 191-225). New York: Churchill Livingstone.

Wynn, K. S. \& Eckel, E. M., (1986). Juvenile rheumatoid arthritis and home physical therapy program compliance, Physical Occupational Therapy Pediatrics, 6 , 55-63. 
APPENDIX A

EVALUATION FORMS 
HAND/ARM THERAPY CENTER FUNCTIOUEL REMABLTIATON SPECLLLLSTS

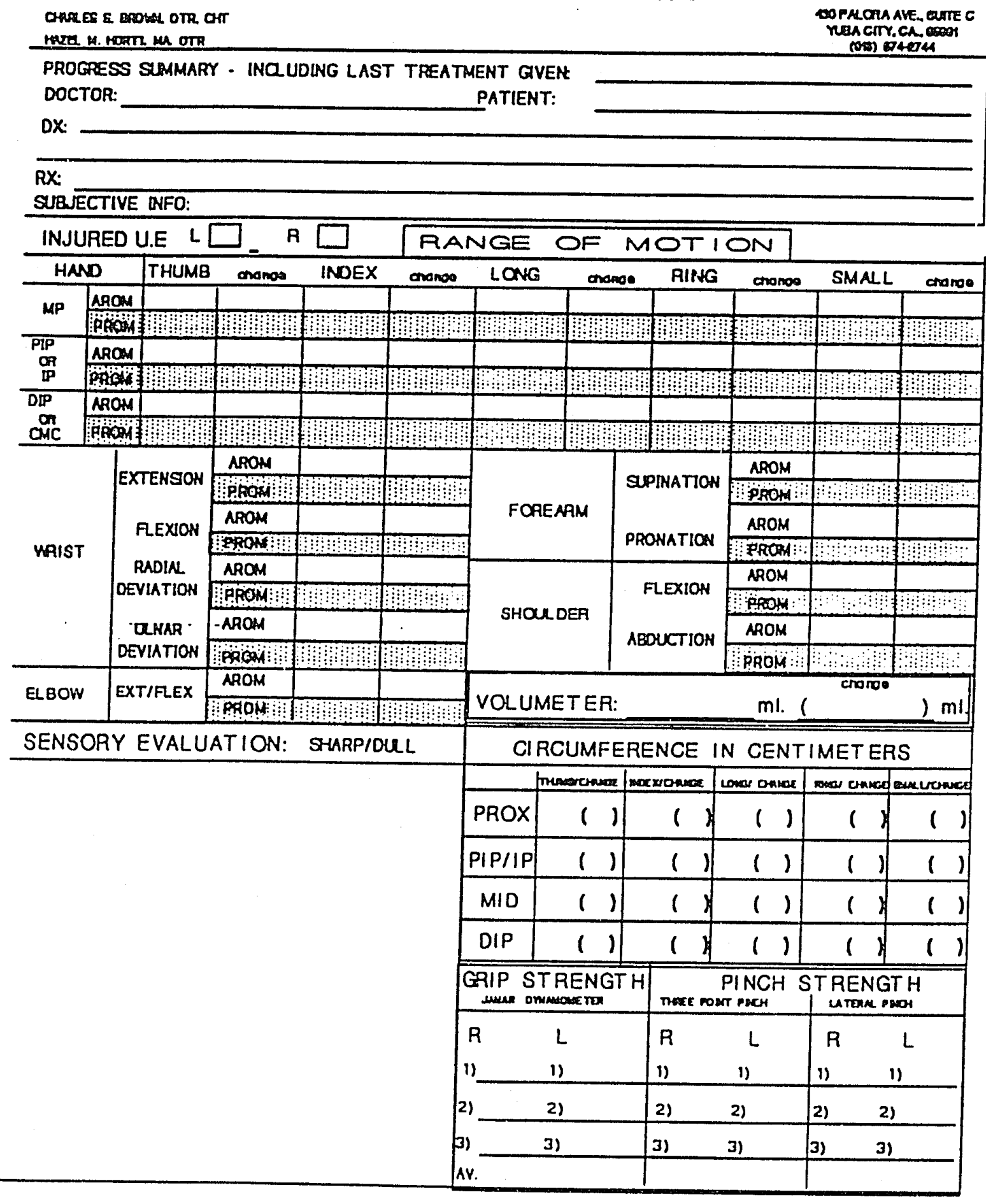


INITIAL EYALUATUN_RERORT OUTWINE

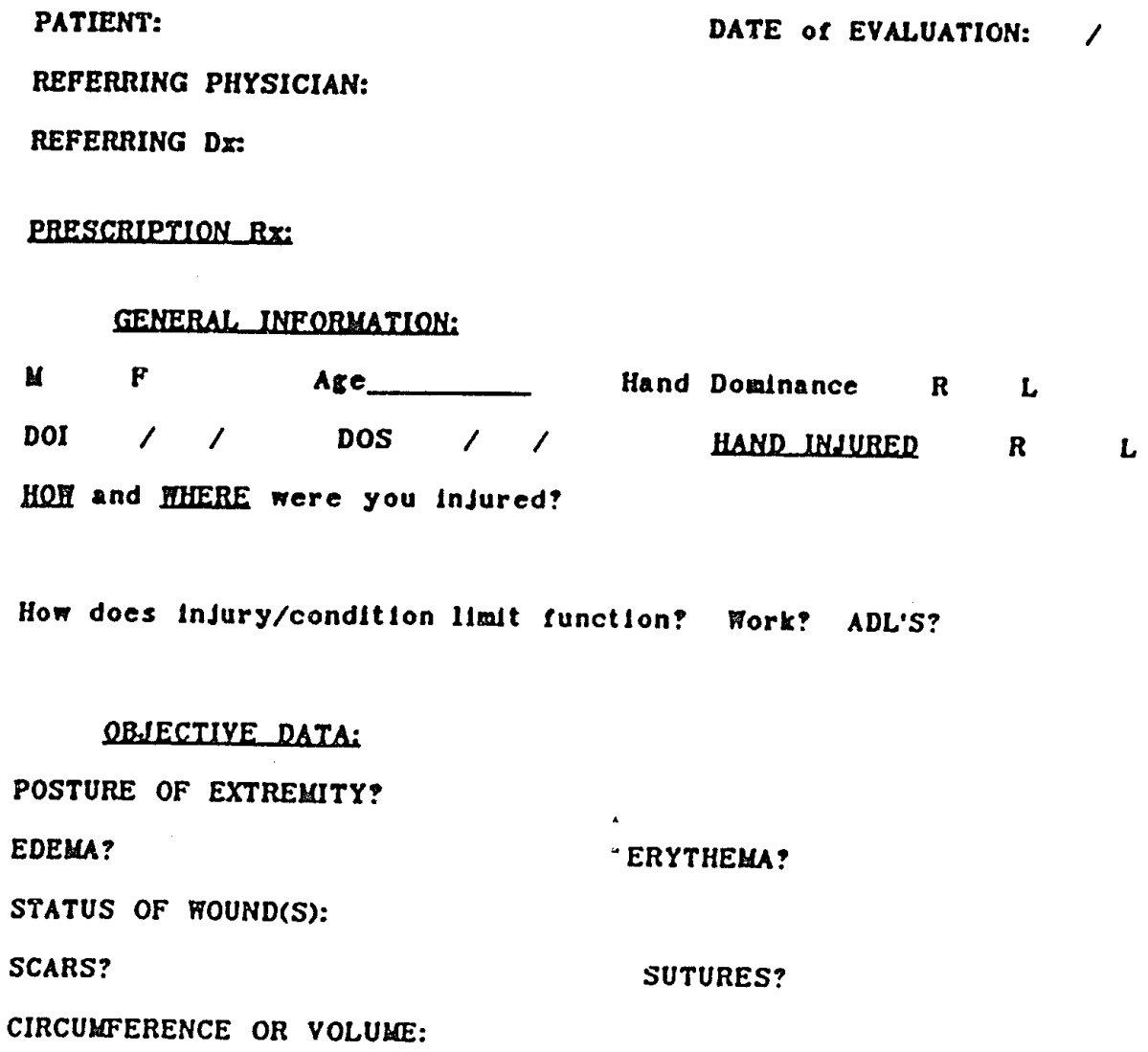


STRENGTH:

Jamar dynamomer - RIGHT

(2nd setting)

\section{LEFT}

Three Polnt P!nch

Lateral Plnch

RIGHT

RIGHT

LEFT

LEFT

SENSIBILITY:

What was done today?

ASSESSLENT:

PROGRAM:

1)

2)

3)

4)

GOALS :

1)

2)

3)

4)

Consulting theraplst 
APPENDIX B

INFORMED CONSENT FORMS 
College of Appllod Bolunoes and Arts - Doportment of Oocupallonel Therept

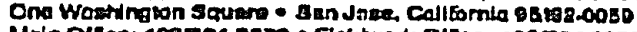

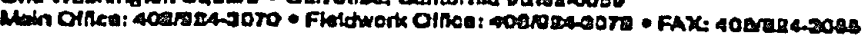

Agreement to Participate in Research

San Jose State University

Responsible Investigator: Hazel M. Horti

Title of Protocol: Home Program Compliance in Trauma Patients with UpperExtremity Joint Stiffness

I have been asked to participate in a research study to investigate the use of home program activities by hand injured persons. The results of this study should further our understanding of the role of home program activities in hand rehabilitation.

I understand that:

1) I will be asked to record my use of the activities recommended by my therapist to be performed daily at home. These are the same activities which would be prescribed If I was not participating in the study.

2) No services I would otherwise be entitled to will be omitted and there is no anticipated risk involved in my participation.

3) The results from this study may be published but any information identified with me will remain confidential and will only be disclosed with my permission.

4) Any questions about my participation in this study will be answered by Hazel Horti, 674-2744. Complaints about the procedures may be made to Dr. Lela Llorens (408) 924-3070. For questions or complaints about research subjects rights, or in the event of research related injury, contact Serena Stanford, PhD. at (408) 924-2480.

5) My consent is given voluntarily without being coerced. I may refuse to participate in this study or in any part of this study, and I may withdraw at any time, without prejudice to my relations with SJSU, the Hand/Arm Therapy Center or my therapist.

6) I have received a copy of the consent form for my file.

I HAVE MADE A DECISION WHETHER OR NOT TO PARTICIPATE MY SIGNATURE INDICATES THAT I HAVE READ THE INFORMATION PROVIDED ABOVE AND THAT I HAVE DECIDED TO PARTICIPATE.

Subject's signature-DDate

Investigator's Signature-_ Date 


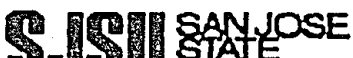

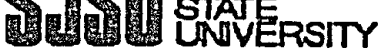

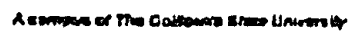

Collage of Applled Rolonoms and Arta - Depertment of Oevupallonel Thesepp Ona Wostringon Squene - Bun Jose. Callfornla $0852-0080$

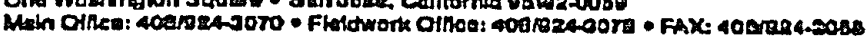

Agreement to Participate in Research San Jose State University

Responsible Investigator: Hazel M. Horti

Title of Protocol: Home Program Compliance in Trauma Patients with UpperExtremity Joint Stiffness

I have been asked to participate in a research study to investigate the use of home program activities by hand injured persons. The results of this study should further our understanding of the role of home program activities in iand rehabilitation.

I understand that:

1) I will be asked to record my use of the activities recommended by my therapist to be performed daily at home. These are the same activities which would be prescribed If I was not participating in the study.

2) No services I would otherwise be entitled to will be omitted and there is no anticipated risk involved in my participation.

3) The results from this study may be published but any information identified with me will remain confidential and will only be disclosed with my permission.

4) Any questions about my participation in this study will be answered by Hazel Horti, 674-2744. Complaints about the procedures may be made to Dr. Lela Llorens (408) 924-3070. For questions or complaints about research subjects rights, or in the event of research related injury, contact Serena Stanford, PhD. at (408) 924-2480.

5) My consent is given voluntarily without being coerced. I may refuse to participate in this study or in any part of this study, and I may withdraw at any time, without prejudice to my relations with SJSU, the Hand/Arm Therapy Center or my therapist.

6) I have received a copy of the consent form for my file.

I HAVE MADE A DECISION WHETHER OR NOT TO PARTICIPATE. MY SIGNATURE INDICATES THAT I HAVE READ THE INFORMATION PROVIDED ABOVE AND THAT I HAVE DECIDED TO PARTICIPATE.

Subject's signature-_-D-Date-

Investigator's Signature-_-_-Date-_-_-_-_-_-_-_- 
APPENDIX C

ACTIVITY INSTRUCTIONS 
This booklet contains the written instructions for your home activity program. You are requested to record the number of times you perform each activity daily as you do them.

It is impertant to record activity use accurately

A record which does not truly reflect your use of the activities will diminish the usefulness of the information to the study in which you have agreed to participate. You are encouraged to use the activities as directed but deviation from the program will not be censured.

You are also requested to note your comfort level while doing the prescribed activities, a. $\mathrm{m}$. and $\mathrm{p} . \mathrm{m}$. by selecting a number from the scale below:

Comfortable 123445678910 Extremely Uncomfortable

A selected group of therapeutic activities prepared by Hazel M. Horti for use in conjunction with occupational therapy treatment at the Hand/Arm Therapy Center 430 Palora Avenue, Yuba City, Ca. 95991. 


\section{ACTIVITY $\sharp 1$ - WRIST ROLLER}

Hang a - oz weight (a ziplock bag containing - cup of water) on the hook.

Grasp wrist roller in both hands, holding it parallel to the floor. Turn the rod, first with one hand then the other, to wind the cord up onto the rod. Allow the weight to unwind the cord. (Powder on your hands will help the rod to slip more easily.) Wind again, turning the rod in the opposite direction. Winding once each way equals one set.

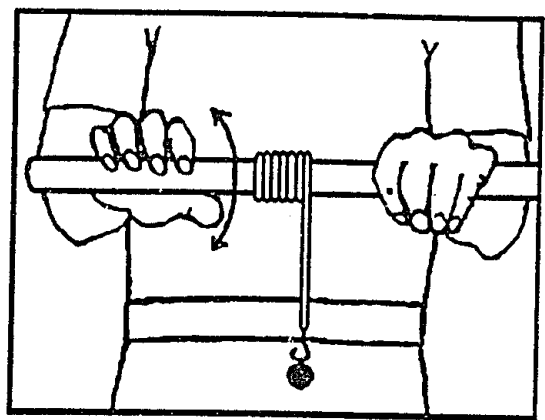

Repeat - - sets, - - times a day.

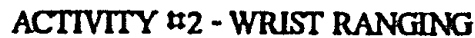

Place your arm on the table with the entire hand extending over the edge, palm down, and let the hand drop towand the floor. Raise your hand as far upwand from the floor as possible, allowing the fingers to cur. Lower your hand toward the floor agnin as far as possible.

Repeat the movement —-times, —-times a day.

Progressive Variations-

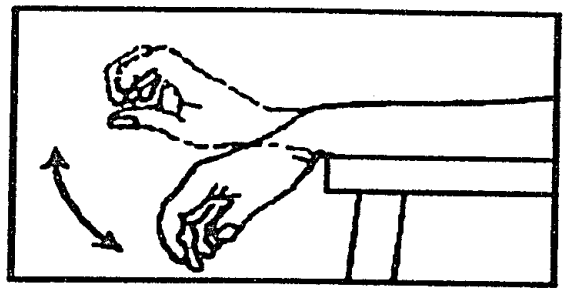

2. Hold a creight (or a can) in your hand while

doing the movement.

b. Hold a Dexterciser I in your hand, with your middle finger centered over the handle, while doing the movement.

Re-set the rubber stops further apart as wrist range increases.

\section{ACTIVITY 3 - BLLATERAL RANGING}

"Praying"- Place your hands, palms touching, in front of your face Lower both hands, pushing the palms together, to chest level, hold for a count of 10 then relax. Reverse "praying"- Place your hands together back to back in front of your abdomen. Raise your hands as high as you can while keeping the backs together, hold for a count of 10 then relax.

Inside Out Stretch - Lace the fingers of both hands together,

palms facing your chest.

Reverse your hands so the palms face away from you and push away from your chest until your elbows are straight. Hold for a count of 10 and relax.

Repeat EACH movement —-times, — a day.

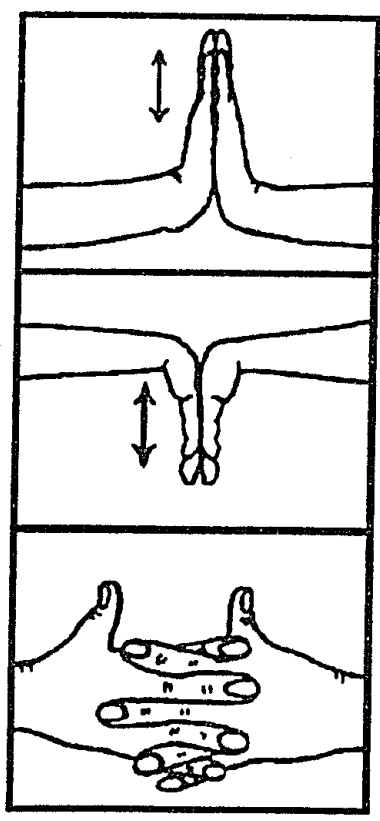




\section{ACTTVITY 44 - METRONOME}

Place your arm on a table, thumb facing up, with the hand hanging over the edge.

Grasp a wooden spoon with the bowl pointing up

Keeping the wrist in neutral, turn your forearm pointing the spoon first left, then right, as far as you can go.

Repeat left and right movements - times, - times a dxy. Progressive Variations-

a. Replace the wand with a Dexterciser $L$. Slide the ball back and forth between the rubber stops. Next time, move the stops further apart. b. Replace the wand with a hammer Hold the hammer close to the head. Next time, hold the hammer further away from the head.

\section{ACTIVITY \#5 - BROOMSTICK}

Lie on your back on a firm surface, arms at your sides and elbows bent at 90 degrees.

Grasp one end of a short (2 foot) piece of broomstick with your strong hand and rest the other end in the thumb web space of your injured hand, with the stick across your chest.

Turn your palm toward the broomstick. Try to touch the stick with as many fingers as possible until you can grasp the stick.

Raise the stick with both hands until your elbows are as straight.

Repeat the movement —_times, - - times a day.

\section{ACTIVTTY 6 - FINGER IN YOUR EAR}

Lie on your back, arms at your sides.

Raise your injured arm and reach across your body toward your opposite ear

Touch your thumb to your ear. Try to put first the index finger, then the long finger, then the ring finger, then the small finger in your ear canal. Eventually, place the palm of your hand flat against your ear.

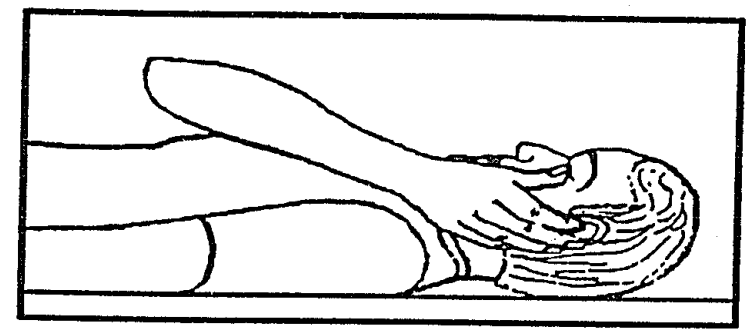

Hold for a count of 10 , then raum your arm to your side and relax.

Repent the movement —-times, _- a day. 
PLActivity 7 - DEXIERCISER II.

Stand, hodding the Dexterciser ii in your injured hand.

Doa't allow the handle to turn in your hand during the movement. Slowly manewver the sliding ball from the red ride to the other side aned back again to complete oae set.

Awoid "whippingl"

Repeat the movement- - times, - a dry.

Progressive variation-

a Sit while daing the movement.

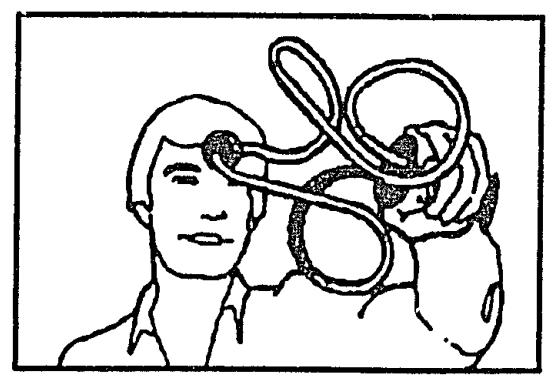

b) Lie down while doing the movement.

Activity 8 - Roll the Beach Ball

Place a large inflated beach ball on a table or desk and stand beside it with your hip against the table.

Press your injured hand firmly againat the top of the ball and roll it as far forwand as you can, then roll it as far backward as you can.

Keep your hand firmly against the ball at all times.

Repeat the movemeat ___times,___times a day

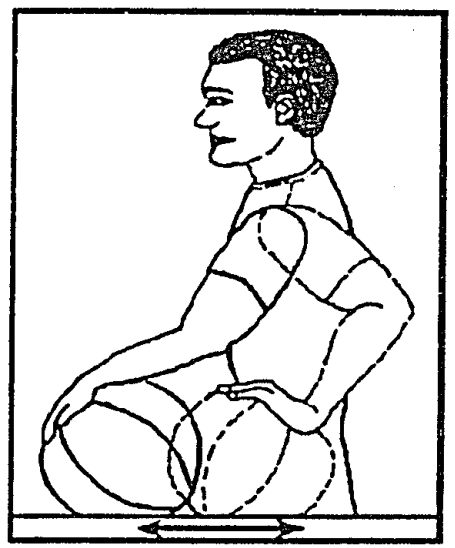

Activity Use Recording Form
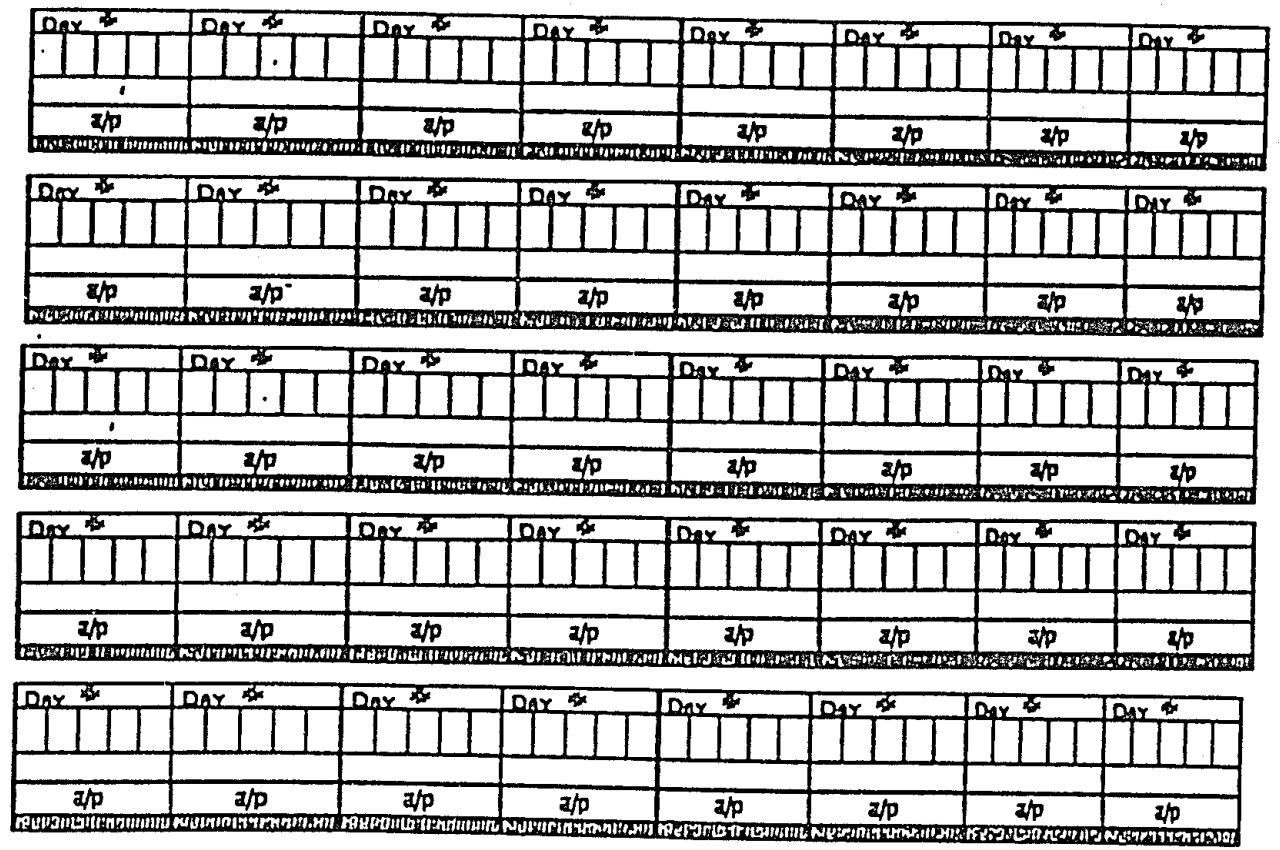
APPENDIX D LETTERS 
HANDIARM THERAPY CENTER

FUACTIONAL REHABIUTANON GPECULLST
420 Palara Ava, Guthe C Yuba Cthy. Ca osent

June 5, 1992 .

As proprletor of the Hand/Arm Therapy Center and employer of llazel H. llortl, O.T.R.. I have agreed to release pertinent mrdical record information on the volunteer subjects who are particlpants in Ms. Hortl's research study. "Home Actlvlty Program Compllance in Trauma Patlents with Upper Extremlty Jolnt stiffness". I have been assured by the Investigator that patlent confidentlality will not be compromised by the releasenof thls information.

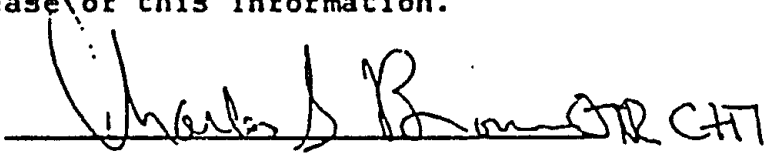


HANDIARM THERAPY CENTER

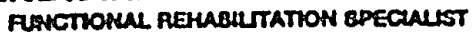

400 Pabra Ave sutto C

Yuba cliy, ch oseor

p16 074 144

Hay, 1992.

Dear Dr.

During the next few weeks I will be conducting a research study into the effect of activity selection on patient compliance with home program activities and the possible relationshlp of moblilty galns to the frequency of use of speclelc activities. I will be Inviting certain patients referred by you to the Hand/Arm Therapy Center for treatment.

since your approval is needed in order for your patients to participate, I hope that you w11l take a few minutes to read the enclosed abstract of my research proposal so you will know what they are beling asked to do. The only departure from normal procedure is that they will be asked to keep a written record of thelr dally use of the home program actlvitles throughout the course of therapy. Activitles for each patient will be chosen, as usual, as approprlate for the patlent's infury with the level of difflculty adjusted as thelr status Improves, therefore risk to the particlpating patients is nil.

I wlll be calling you about potentlal partlcipants as they present themselves to obtain your OK. IE you have any questions about the study please call me any Monday, Wednesday or Friday at 674-2744.

yours truly,

Hazel M. Hort1, O.T.R. 